\title{
Synthesis and evaluation of novel serotonin 4 receptor radiotracers for single photon emission computed tomography
}

\author{
Julien Lalut, ${ }^{\mathrm{a}}$ Benjamin B. Tournier, ${ }^{\mathrm{b}}$ Thomas Cailly, ${ }^{\mathrm{a}}$ Cédric Lecoutey, ${ }^{\mathrm{a}}$ Sophie Corvaisier, ${ }^{\mathrm{a}}$ \\ Audrey Davis, ${ }^{a}$ Céline Ballandonne, ${ }^{a}$ Marc Since, ${ }^{a}$ Philippe Millet, ${ }^{b}$ Frédéric Fabis, ${ }^{a}$ Patrick \\ Dallemagne, ${ }^{a}$ Christophe Rochais ${ }^{\mathrm{a}, ~}{ }^{*}$ \\ ${ }^{a}$ Normandie Univ, UNICAEN, CERMN, F-14032 Caen, France \\ ${ }^{b}$ Hôpitaux Universitaires de Genève, Département de Santé Mentale et de Psychiatrie, Service \\ de Psychiatrie Générale, Unité des Biomarqueurs de Vulnérabilité, Chemin du Petit-Bel-Air, 2, \\ CH-1225 Genève, Switzerland
}

Keywords: Molecular Imaging, radioligand, serotonin, 5-HT 4 , SPECT

* To whom correspondence should be addressed. Phone: +33 -2-3156-6813. Fax: +33 -2-31566803. E-mail: christophe.rochais@unicaen.fr

\begin{abstract}
Despite its implication in several physiological and pathological processes the serotonin subtype4 receptor $\left(5-\mathrm{HT}_{4} \mathrm{R}\right)$ has seen limited effort for the development of radiolabeling agent especially concerning single photon emission computed tomography (SPECT). Bearing an ester function, the available ligands are rapidly susceptible to hydrolysis which limits their use in vivo. In this study the synthesis of iodinated benzamide and ketone analogs were described. Their affinity for the $5-\mathrm{HT}_{4} \mathrm{R}$ and their lipophilicity were evaluated and the most promising derivatives were evaluated ex vivo for their binding to the receptor and for their ability to displace the reference ligand $\left[{ }^{125} \mathrm{I}\right]-\mathrm{SB} 207710$.
\end{abstract}

\section{Introduction}

Serotonin (5-hydroxytryptamine, 5-HT) plays a central role in neurotransmission through its interaction with several receptor subtypes, and the deregulation of this system has been implicated in numerous pathologies [1]. In order to determine the implication of each receptor

(C) 2016. This manuscript version is made available under the Elsevier user license http://www.elsevier.com/open-access/userlicense/1.0/ 
subtypes in these diseases, intense research has been conducted during the last few years to develop selective radioligands of interest for positron emission tomography (PET) and single photon emission computed tomography (SPECT) imaging [2,3]. Among those receptors, 5-HT $\mathrm{R}$ are of particular interest. They have been described for the first time by Dumuis in 1988 and are positively linked to adenylate cyclase and could control the release of a wide variety of neurotransmitters [4]. These receptors are expressed in the central nervous system (CNS) and control brain physiological functions such as learning and memory, feeding and mood behaviour but they are also located in the periphery and are implicated in gastro-intestinal transit [5]. Interactions with peripheral 5- $\mathrm{HT}_{4} \mathrm{R}$ appear beneficial in gastrointestinal disorders [6], while interactions with the central 5- $\mathrm{HT}_{4} \mathrm{R}$, mainly with agonists, result in cognitive improvement after chronic or acute administration [7]. For this reason it is now postulated that several major devastating illnesses could benefit from 5- $\mathrm{HT}_{4} \mathrm{R}$-directed therapy including Alzheimer's disease (AD) [8] or depression [9].

Over the years, potent and selective ligands have been developed towards the 5-HT 4 R [10] which are mainly based on a typical 4-amino-5-chloro-2-methoxybenzoyl residue already described in the non-selective benzamide metoclopramide [11], as well as in the benzoate ML10302 and the benzophenone RS67,333 (Figure 1A) [12]. In order to specify in vivo the 5-HT4 $\mathrm{R}$ physiological or pathological role, selective radioligands have been developed for SPECT and PET such as benzodioxane $\left[{ }^{123} \mathrm{I}\right] \mathrm{SB}-207710\left(\left[{ }^{123} \mathrm{I}\right] \mathbf{1}\right)$ [13] or its chlorinated analogue $\left[{ }^{11} \mathrm{C}\right] \mathrm{SB}-207145$ $\left(\left[{ }^{11} \mathrm{C}\right] 2\right)$ (Figure 1B) [14]. The latter remains the only radiotracer that has been evaluated in human studies [15]. Two radiotracers containing fluorine-18 $\left[{ }^{18} \mathrm{~F}\right] \mathrm{MNI}-698\left(\left[{ }^{18} \mathrm{~F}\right] 3\right)$ and $\left[{ }^{18} \mathrm{~F}\right] \mathrm{MNI}-699\left(\left[{ }^{18} \mathrm{~F}\right] 4\right)$ were described in the same chemical series but possessing a radioactive atom as a substituent of the piperidine alkyl chain [16]. Among them $\left[{ }^{18} \mathrm{~F}\right] \mathbf{3}$ gave promising results for imaging $5-\mathrm{HT}_{4} \mathrm{R}$ in the brain in monkey $[17,18]$. More recently two novel tracers $\left[{ }^{11} \mathrm{C}\right] \mathrm{RX}-1\left(\left[{ }^{11} \mathrm{C}\right] 5\right)$ and $\left[{ }^{18} \mathrm{~F}\right] \mathrm{RX}-2\left(\left[{ }^{18} \mathrm{~F}\right] \mathbf{6}\right)$ were developed and evaluated for PET imaging [19]. However each of theses ligands containing an ester function are susceptible to ester hydrolysis in vivo which could limit their accuracy. Other chemical series were then explored with the recent development of azaphenanthrene derivatives $\left[{ }^{125} \mathrm{I}\right] 7$ and $\left[{ }^{125} \mathrm{I}\right] \mathbf{8}$ (Figure 1) [20,21]. The amide modulation could be of particular interest since this function is present in R-91150 which was developed as brain 5- $\mathrm{HT}_{2 \mathrm{~A}} \mathrm{R}$ SPECT radiotracers $[23,24]$. 


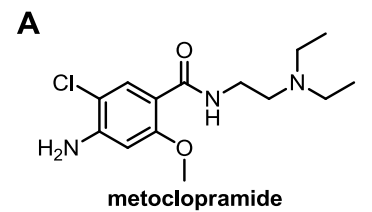

B<smiles>[X]c1cc(C(=O)OCC2CCN([R])CC2)c2c(c1N)OCCO2</smiles>

$\left[{ }^{123} \mathrm{I}\right] 1$ ([ $\left.\left.{ }^{123} \mathrm{I}\right]-\mathrm{SB} 207710\right), \mathrm{X}={ }^{123} \mathrm{I}, \mathrm{R}_{1}=n-\mathrm{Bu}$ $\left[{ }^{11} \mathrm{C}\right] 2\left(\left[{ }^{11} \mathrm{C}\right]-\mathrm{SB} 207145, \mathrm{X}=\mathrm{Cl}\right), \mathrm{R}_{1}={ }^{11} \mathrm{CH}_{3}$ $\left[{ }^{18} \mathrm{~F}\right] 3$ ([ $\left.\left.{ }^{18} \mathrm{~F}\right]-\mathrm{MNI}-698, \mathrm{X}=\mathrm{Cl}\right), \mathrm{R}_{1}=\mathrm{C}_{2} \mathrm{H}_{4}{ }^{18} \mathrm{~F}$ $\left[{ }^{18} \mathrm{~F}\right] 4$ ([ $\left.{ }^{18} \mathrm{~F}\right]-\mathrm{MNI}-699, \mathrm{X}=\mathrm{Cl}$ ), $\mathrm{R}_{1}=\mathrm{C}_{3} \mathrm{H}_{7}{ }^{18} \mathrm{~F}$
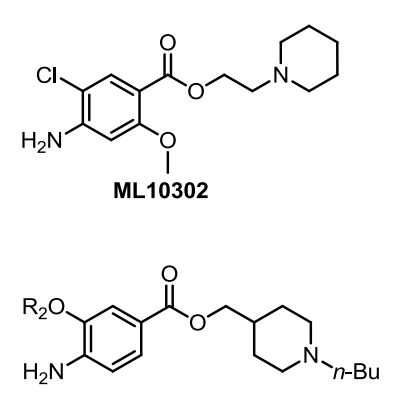

$\left[{ }^{11} \mathrm{C}\right] 5\left(\left[{ }^{11} \mathrm{C}\right]-\mathrm{RX}-1\right), \mathrm{R}_{2}={ }^{11} \mathrm{CH}_{3}$ $\left[{ }^{18} \mathrm{~F}\right] 6\left(\left[{ }^{18} \mathrm{~F}\right]-\mathrm{RX}-2\right), \mathrm{R}_{2}=\mathrm{CD}_{2}{ }^{18} \mathrm{~F}$
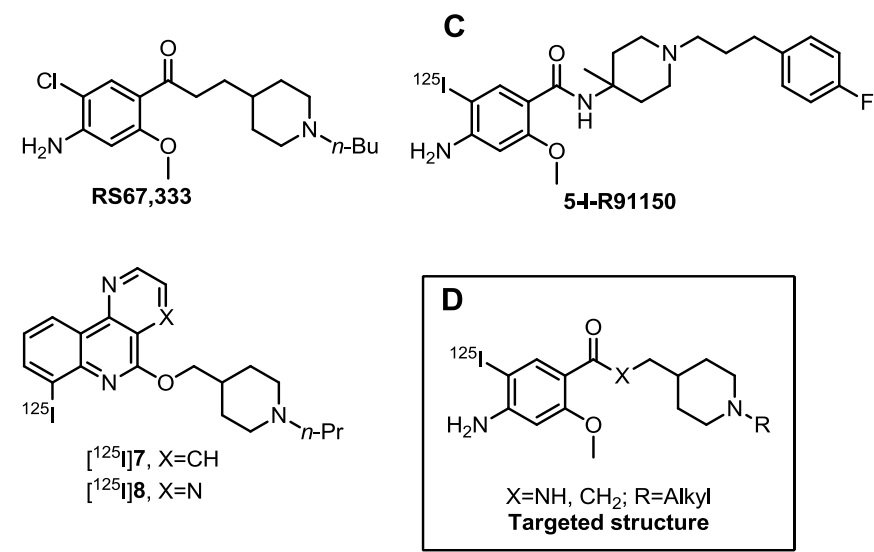

Figure 1. A: Structures of reference 5-HT4 $\mathrm{R}$ ligands; B: 5- $\mathrm{HT}_{4} \mathrm{R}$ PET and SPECT radiotracers; C: $5-\mathrm{HT}_{2 \mathrm{~A}} \mathrm{R}$ SPECT radiotracer; D: targeted structures.

\section{Results}

\subsection{Chemistry}

Despite the traditionally reported strategy for obtaining iodinated single photon emission computed tomography radiotracers, based on a iododestannylation reaction of a stannylated precursor [25], and while our structures appear to be favorable for this reaction, we focused on the introduction of iodine atoms on non-functionalized precursors using electrophilic aromatic substitution reactions.

Initially, we planned to synthesize iodinated derivatives without radioactive source, by generating $\mathrm{I}_{2}$ from $\mathrm{NaI}$ using an oxidant in acidic conditions [26]. Obtaining the iodinated derivatives from the non-functionalized compounds allowed us to confirm the selective halogenation at the expected position, to evaluate their potential affinity toward $5-\mathrm{HT}_{4} \mathrm{R}$ and to validate the feasibility of this procedure for the radiolabeling of our non-functionalized derivatives. This strategy will also allow us to avoid the synthesis of stannylated precursor, typically used in this kind of radiolabeling strategies.

For the design of non-functionalized aryl ketone derivatives, acids $\mathbf{1 1 a - b}$ were synthesized in a three-step reaction from 4-aminosalicylic acid: an esterification of carboxylic acid, an alkylation of phenol with an ethyl or a 2-(fluoro)ethyl chain and a saponification reaction (Scheme 1). Compounds 14a-b were finally prepared according to the general route as previously described: 
formation of $\beta$-keto ester, subsequent alkylation with a piperidine derivative, saponificationdecarboxylation reaction, deprotection of tert-butoxycarbonyl group under acidic conditions and alkylation of the piperidine with (bromomethyl)cyclohexane (Scheme 1) [27].

\section{Scheme 1. Synthetic route of aryl ketone derivatives $14 a-b^{a}$}
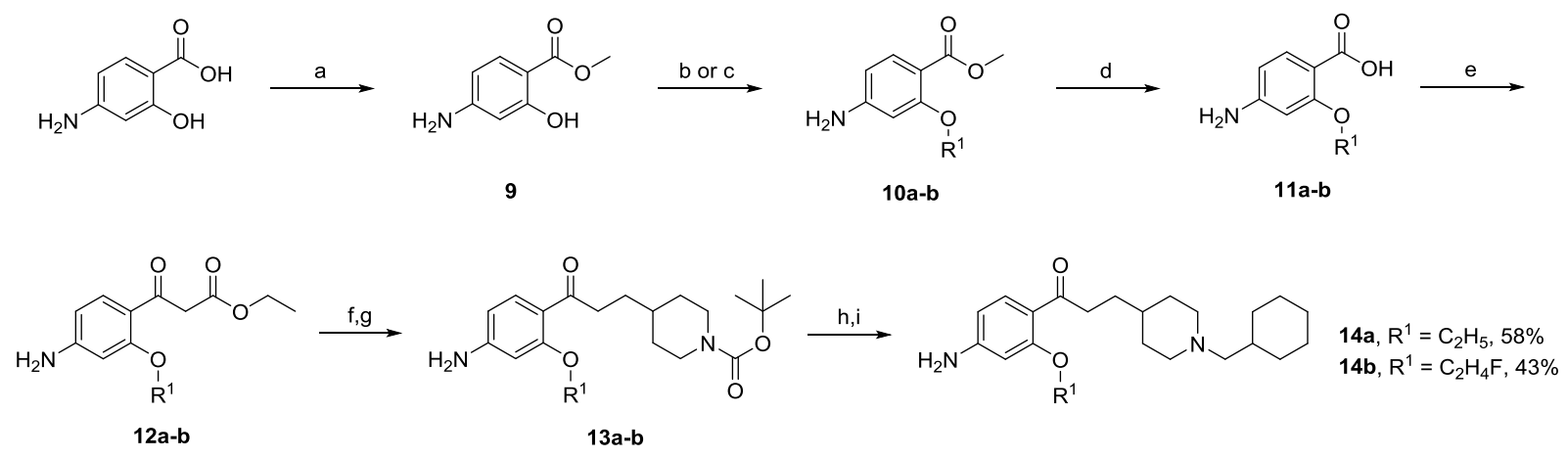

${ }^{a}$ Reagents, conditions and yields: (a) $\mathrm{H}_{2} \mathrm{SO}_{4}$ cc., $\mathrm{MeOH}, 16 \mathrm{~h}$, reflux, $90 \%$; (b) iodoethane, $\mathrm{K}_{2} \mathrm{CO}_{3}$, DMF, $70{ }^{\circ} \mathrm{C}$, overnight, $61 \%$; (c) 2 -fluoroethyl 4-methylbenzenesulfonate, $\mathrm{K}_{2} \mathrm{CO}_{3}, \mathrm{DMF}, 110^{\circ} \mathrm{C}, 2 \mathrm{~h}, 62 \%$; (d) $1 \mathrm{~N} \mathrm{NaOH}$ aq., EtOH, rt, overnight, 94-96\%; (e) CDI, dry THF, rt, $15 \mathrm{~h}$, then potassium 3-ethoxy-3-oxopropanoate, $\mathrm{MgCl}_{2}, 40^{\circ} \mathrm{C}, 24 \mathrm{~h}, 23-36 \%$; (f) tert-butyl 4-(iodomethyl)piperidine-1-carboxylate, $\mathrm{K}_{2} \mathrm{CO}$, $\mathrm{DMF}$, rt, $48 \mathrm{~h}$; (g) $\mathrm{KOH}, \mathrm{EtOH} / \mathrm{H}_{2} \mathrm{O}(5: 1)$, reflux, 5h, 70-74\% over two steps; (h) TFA, DCM, rt, 1h; (i) bromomethylcyclohexane, $\mathrm{K}_{2} \mathrm{CO}_{3}, 110^{\circ} \mathrm{C}, 5 \mathrm{~h}, 43-58 \%$ over two steps.

For the design of non-functionalized benzamide derivatives, aminopiperidine chains 16a-b were synthesized in a two-step reaction, first by alkylation of the piperidine moiety with alkyl halides, then by reduction of amides using $\mathrm{LiAlH}_{4}$. Target compounds $\mathbf{1 7 a - d}$ were finally obtained by a peptide coupling between carboxylic acids 11a-c (previously synthesized, except commercially available 4-amino-2-methoxy-benzoic acid 11c) and substituted aminopiperidines 16a-b (Scheme 2).

\section{Scheme 2. Synthetic route of benzamide derivatives $17 a-d^{b}$}<smiles>CC(C)CC(C)C</smiles><smiles>[R]N1CCC(C(N)=O)CC1</smiles><smiles>[R]N1CCC(CN)CC1</smiles>

16a, $\mathrm{R}^{1}=\mathrm{C}_{3} \mathrm{H}_{7}, 71 \%$

15a-b<smiles>[R]Oc1cc(N)ccc1C(=O)O</smiles>

11a-c<smiles>[R]N1CCC(CN)CC1</smiles><smiles>CC(C)C</smiles><smiles>[R]Oc1cc(N)ccc1C(=O)NCC1CCN([R])CC1</smiles>

17a, $\mathrm{R}^{1}=\mathrm{C}_{2} \mathrm{H}_{5}, \mathrm{R}^{2}=\mathrm{C}_{7} \mathrm{H}_{13}, 28 \%$ 17b, $\mathrm{R}^{1}=\mathrm{C}_{2} \mathrm{H}_{4} \mathrm{~F}, \mathrm{R}^{2}=\mathrm{C}_{7} \mathrm{H}_{13}, 44 \%$ 17c, $\mathrm{R}^{1}=\mathrm{CH}_{3}, \mathrm{R}^{2}=\mathrm{C}_{7} \mathrm{H}_{13}, 17 \%$ 17d, $\mathrm{R}^{1}=\mathrm{CH}_{3}, \mathrm{R}^{2}=\mathrm{C}_{3} \mathrm{H}_{7}, 25 \%$ 
${ }^{b}$ Reagents, conditions and yields: (j) alkyl-halogenated derivatives, $\mathrm{K}_{2} \mathrm{CO}_{3}$, EtOH, reflux, 15-24h, 92-93\%; (k) LiAlH $\mathrm{H}_{4}$, dry $\mathrm{THF}$, addition $0{ }^{\circ} \mathrm{C}$ then rt, 1-2h, reflux, 3h, 71-96\%; (l) EDCI, HOBt, $\mathrm{Et}_{3} \mathrm{~N}, \mathrm{DMF}, \mathrm{rt}, 18-72 \mathrm{~h}, 17-44 \%$.

Iodinations from non-functionalized aryl ketone derivatives $\mathbf{1 4 a - b}$ and benzamide derivatives 17a-d were performed using $\mathrm{NaI}$ as the source of iodine in a mixture of acetic acid/hydrogen peroxide solution 30\%. A total conversion was observed, after a purification by flash chromatography on silica gel column and compounds 18a-f were obtained in 18-71\% isolated yields (Scheme 3). Selective halogenation at the expected position validated the feasibility of our strategy.

\section{Scheme 3. Synthesis of iodinated compounds $18 \mathrm{a}-\mathrm{f}^{c}$ and ${ }^{125}$ I radiolabeling of compounds} $17 \mathbf{a}-\mathbf{b}^{c}$
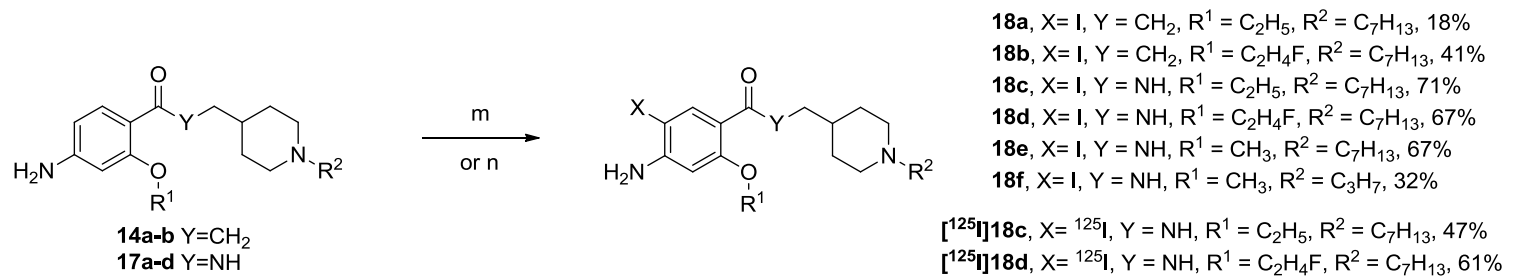

${ }^{c}$ Reagents, conditions and yields: (m) NaI, acetic acid/30\% $\mathrm{H}_{2} \mathrm{O}_{2} 2: 1$, rt, 1-2h, 18-71\%; (n) Na ${ }^{125}$, acetic acid/30\% $\mathrm{H}_{2} \mathrm{O}_{2} 2: 1$, rt, $30 \mathrm{~min}, 47-61 \%$.

\subsection{Synthesis of radioligand}

The effectiveness of our synthetic route was based on a final electrophilic iodination step. Considering the in vitro activities of the iodinated compounds (Table 1), radioiodination of 17ab was performed (Scheme 3). $\left[{ }^{125} \mathrm{I}\right] \mathbf{1 8 c}$-d were obtained using $\mathrm{Na}^{125} \mathrm{I}$ as the radioactive iodine source and peracetic acid (formed in situ by the reaction of $\mathrm{H}_{2} \mathrm{O}_{2}$ and acetic acid) as the oxidant in order to in situ generate iodine and to conduct the aromatic electrophilic substitution (Scheme 4). Radiotracers were isolated by a linear gradient HPLC run.

\subsection{In vitro assays}

According to the work described by Grossman et al.,[28] precursors 14a-b, 17a-d and final derivatives 18a-f, were evaluated in vitro for their potential guinea-pig 5-HT4 $\mathrm{R}$ affinity using a displacement assay of the tritiated ligand $\left[{ }^{3} \mathrm{H}\right]-\mathrm{GR} 113808$, a specific and highly potent $5-\mathrm{HT}_{4} \mathrm{R}$ antagonist used to label specific binding sites in human or guinea-pig brain (Table 1). 
In order to evaluate the influence of these modulations on the physicochemical properties of the novel ligands 18a-f, the evaluation of their capacity to cross the blood-brain barrier (BBB) was performed using a PAMPA assay and their lipophilicities were evaluated by mean of the determination of their $\log \mathrm{P}$ which were calculated using either MarvinSketch 5.2.6 or Molinspiration and estimated using chromatographic method adapted from the previous work of reported by Henchoz et al.[29]

Table 1. 5-HT 4 R affinity for the compounds 14a-b, 17a-d and 18a-f; calculated and measured lipophilicities and permeabilities in the PAMPA-BBB assay with their predictive penetration in the CNS for the compounds 18a-f.
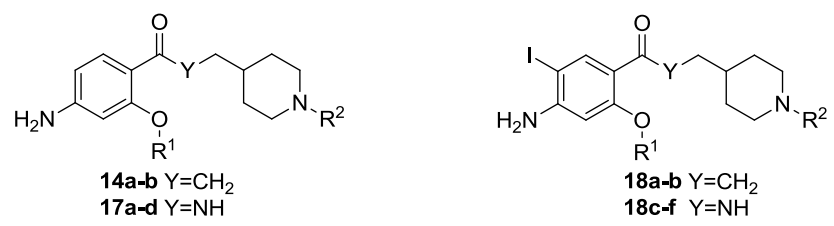

\begin{tabular}{|c|c|c|c|c|c|c|c|c|}
\hline \multirow[b]{2}{*}{ Compound } & \multirow[b]{2}{*}{$\mathbf{Y}$} & \multirow[b]{2}{*}{$\mathbf{R}^{1}$} & \multirow[b]{2}{*}{$\mathbf{R}^{2}$} & \multirow{2}{*}{$\begin{array}{c}K_{\mathrm{i}} \text { 5-HT } 4 \mathrm{R}(\mathrm{nM}) \\
\text { \% Inhibition } 10^{-6} \mathrm{M} / 1^{-8} \mathrm{M}\end{array}$} & \multicolumn{2}{|c|}{ Lipophilicity } & \multicolumn{2}{|c|}{ Permeability } \\
\hline & & & & & $\begin{array}{l}c \log P^{a}- \\
c \log P^{b}\end{array}$ & $\log P$ exp. & $\begin{array}{c}P \mathrm{e} \\
\left(10^{-6} \mathrm{~cm}_{.}^{-1}\right)\end{array}$ & Prediction \\
\hline $14 a$ & $\mathrm{CH}_{2}$ & $\mathrm{C}_{2} \mathrm{H}_{5}$ & & $\begin{array}{c}24.7 \pm 5.3(\mathrm{n}=3)^{\mathrm{d}} \\
100 \% / 38 \%\end{array}$ & n.d. & n.d. & n.d. & n.d. \\
\hline $18 \mathbf{a}$ & $\mathrm{CH}_{2}$ & $\mathrm{C}_{2} \mathrm{H}_{5}$ & & $\begin{array}{c}86 \pm 19.4(\mathrm{n}=3)^{\mathrm{d}} \\
100 \% / 65 \%\end{array}$ & $\begin{array}{c}5.06- \\
6.13\end{array}$ & $6.4 \pm 0.5$ & 8.08 & CNS +/- \\
\hline $14 b$ & $\mathrm{CH}_{2}$ & $\mathrm{C}_{2} \mathrm{H}_{4} \mathrm{~F}$ & & $\begin{array}{c}39.9 \pm 5.3(\mathrm{n}=3)^{\mathrm{d}} \\
100 \% / 27 \%\end{array}$ & n.d. & n.d. & n.d. & n.d. \\
\hline $18 b$ & $\mathrm{CH}_{2}$ & $\mathrm{C}_{2} \mathrm{H}_{4} \mathrm{~F}$ & & $\begin{array}{c}521 \pm 261(\mathrm{n}=3)^{\mathrm{d}} \\
100 \% / 22 \%\end{array}$ & $\begin{array}{l}4.91- \\
6.05\end{array}$ & $5.6 \pm 0.4$ & 10.36 & CNS +/- \\
\hline $17 \mathbf{a}$ & $\mathrm{NH}$ & $\mathrm{C}_{2} \mathrm{H}_{5}$ & & $\begin{array}{c}6.9 \pm 0.6(\mathrm{n}=3)^{\mathrm{d}} \\
100 \% / 51 \%\end{array}$ & n.d. & n.d. & n.d. & n.d. \\
\hline $18 c$ & $\mathrm{NH}$ & $\mathrm{C}_{2} \mathrm{H}_{5}$ & & $\begin{array}{c}8.64 \pm 0.37(n=3)^{d} \\
100 \% / 20 \%\end{array}$ & $\begin{array}{l}3.95- \\
5.63\end{array}$ & $4.9 \pm 0.5$ & 24.38 & $\mathrm{CNS}+$ \\
\hline $17 b$ & $\mathrm{NH}$ & $\mathrm{C}_{2} \mathrm{H}_{4} \mathrm{~F}$ & & $\begin{array}{c}8.1 \pm 3.4(\mathrm{n}=3)^{\mathrm{d}} \\
100 \% / 38 \%\end{array}$ & n.d. & n.d. & n.d. & n.d. \\
\hline 18d & $\mathrm{NH}$ & $\mathrm{C}_{2} \mathrm{H}_{4} \mathrm{~F}$ & & $\begin{array}{c}14.7 \pm 2.9(\mathrm{n}=3)^{\mathrm{d}} \\
100 \% / 30 \%\end{array}$ & $\begin{array}{l}3.79- \\
5.55\end{array}$ & $5.2 \pm 0.4$ & 32.29 & $\mathrm{CNS}+$ \\
\hline
\end{tabular}




\begin{tabular}{|c|c|c|c|c|c|c|c|c|}
\hline $17 \mathrm{c}$ & $\mathrm{NH}$ & $\mathrm{CH}_{3}$ & & $\begin{array}{c}\text { n.d. } \\
72 \% / 40 \% \mathrm{~g}\end{array}$ & n.d. & n.d. & n.d. & n.d. \\
\hline $18 \mathrm{e}$ & $\mathrm{NH}$ & $\mathrm{CH}_{3}$ & & $\begin{array}{c}13.9 \pm 3.7(\mathrm{n}=3)^{\mathrm{c}} \\
100 \% / 29 \%\end{array}$ & $\begin{array}{c}3.59- \\
5.25\end{array}$ & $5.0 \pm 0.4$ & 31.60 & $\mathrm{CNS}+$ \\
\hline 17d & $\mathrm{NH}$ & $\mathrm{CH}_{3}$ & & $\begin{array}{l}\text { n.d. } \\
79 \% / 5 \% \mathrm{~g}\end{array}$ & n.d. & n.d. & n.d. & n.d. \\
\hline $18 f$ & $\mathrm{NH}$ & $\mathrm{CH}_{3}$ & $\sqrt[2]{2}$ & $\begin{array}{c}68.7 \pm 11.4(\mathrm{n}=3)^{\mathrm{c}} \\
96 \% / 11 \%\end{array}$ & $\begin{array}{c}2.36- \\
3.84\end{array}$ & $3.5 \pm 0.4$ & 22.68 & $\mathrm{CNS}+$ \\
\hline
\end{tabular}

n.d. not determined $/{ }^{\mathrm{a}}$ calculated with MarvinSketch $/{ }^{\mathrm{b}}$ calculated with Molinspiration $/{ }^{\mathrm{c}}$ guinea pig receptors $/{ }^{\mathrm{d}}$ human receptors

\subsection{Imaging experiments}

As detailed in the discussion section the most active in vitro compounds 18c-d were selected for further preclinical evaluation as 5-HT 4 R SPECT radiotracers. Following their radioiodination $\left[{ }^{125} \mathrm{I}\right] \mathbf{1 8 c}$ and $\left[{ }^{125} \mathrm{I}\right] \mathbf{1 8 d}$ were injected in the tail vein of rats and SPECT images were obtained (Figure 2). As illustrated by representative images $\left[{ }^{125} \mathrm{I}\right] \mathbf{1 8 c}$ and $\left[{ }^{125} \mathrm{I}\right] \mathbf{1 8 d}$ are able to enter the brain and are detected by the SPECT scanner. However, the brain distribution of both $\left[{ }^{125} \mathrm{I}\right] \mathbf{1 8 c}$ and $\left[{ }^{125} \mathrm{I}\right] \mathbf{1 8 d}$ did not show a specific accumulation in $5-\mathrm{HT}_{4} \mathrm{R}$ rich region, such as olfactory tubercles, caudate-putamen, in comparison with the cerebellum, a region devoid of 5- $\mathrm{HT}_{4} \mathrm{R}$ according to in vivo SPECT imaging and ex vivo autoradiograms (Figures 2-3). 


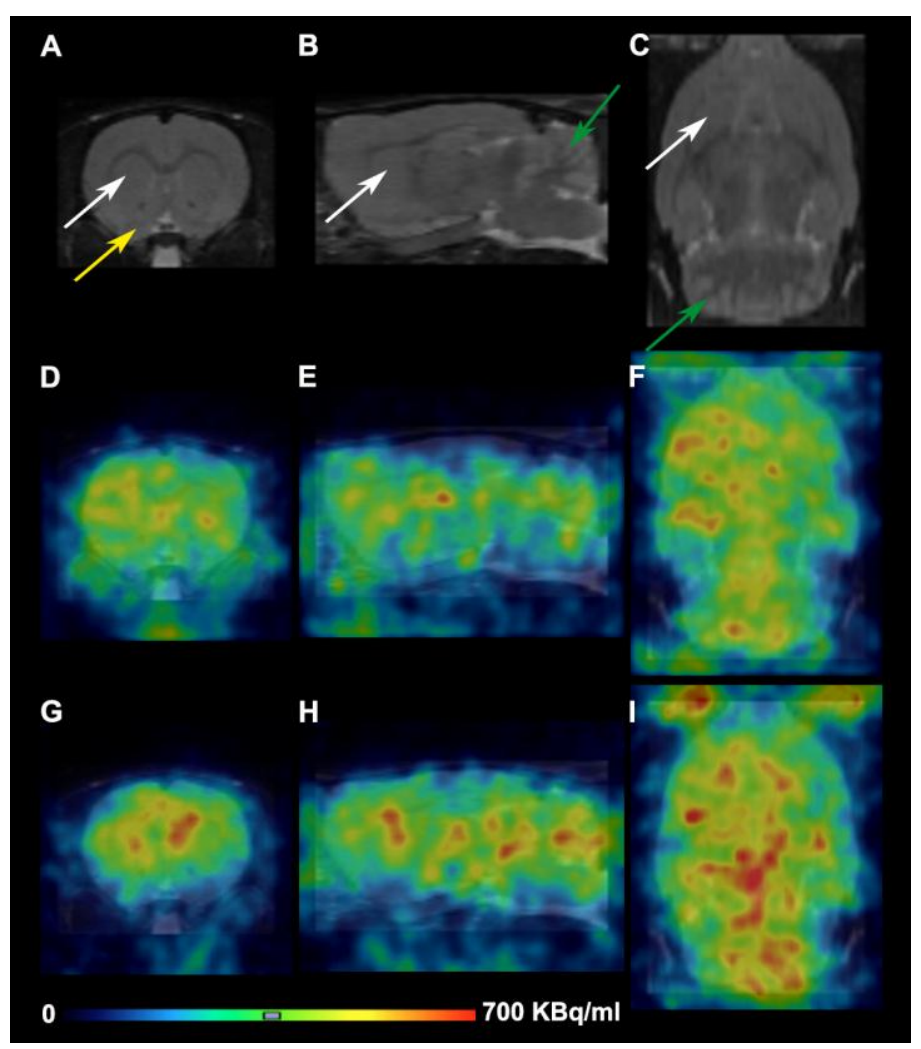

Figure 2. In vivo SPECT imaging showing activity distribution in the brain after injection of $\left[{ }^{125} \mathrm{I}\right] 18 \mathrm{c}$ or $\left[{ }^{125} \mathrm{I}\right] \mathbf{1 8 d}$. Representative MRI images in coronal (A), sagittal (B) and axial (C) planes. Arrows indicate areas of interest: olfactory tubercles (yellow), Caudate-putamen (white) and cerebellum (green). Images of SPECT scan between 10 and 60 minutes after injection of $\left[{ }^{125} \mathrm{I}\right] \mathbf{1 8 c}(\mathrm{D}-\mathrm{F})$ or $\left[{ }^{125} \mathrm{I}\right] \mathbf{1 8 d}(\mathrm{G}-\mathrm{I})$ coregistered with MRI template.
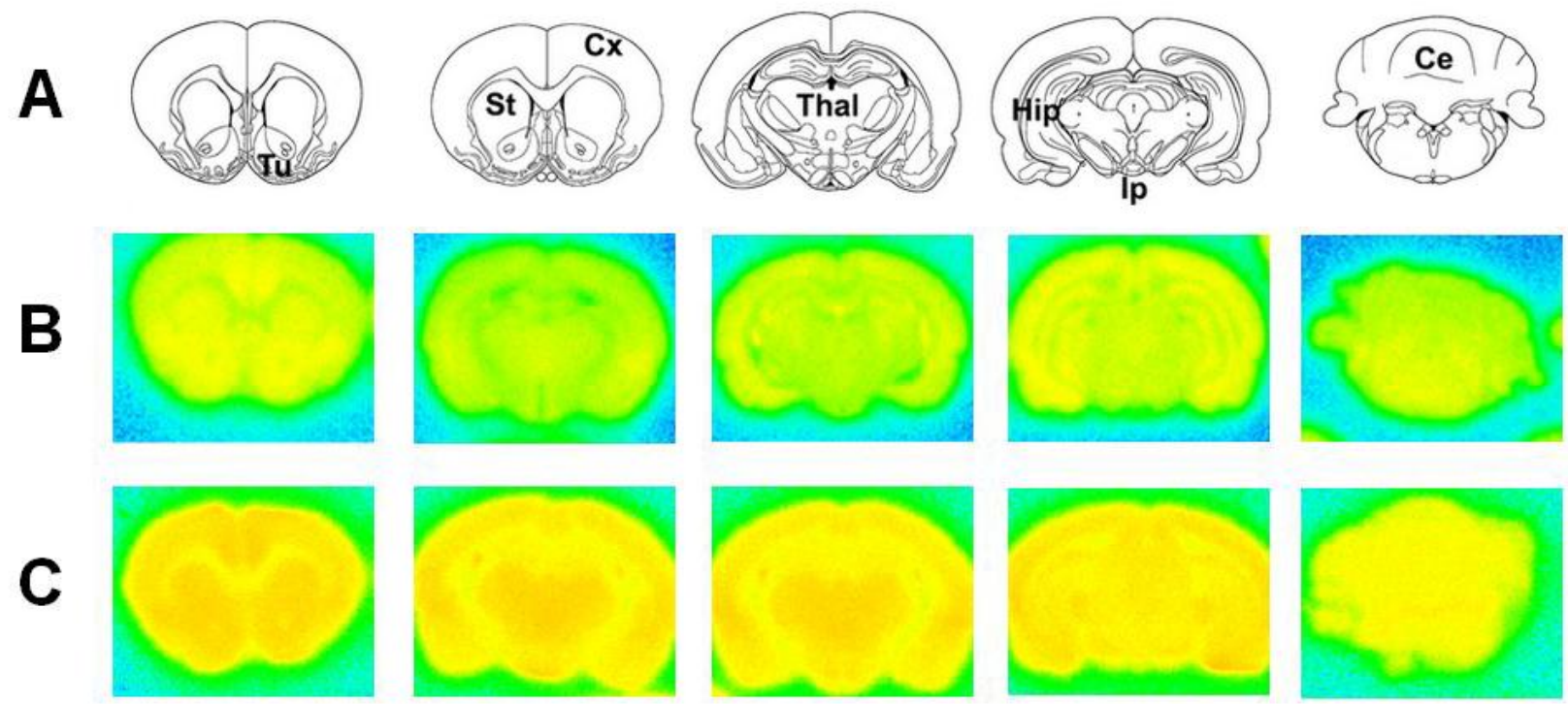
Figure 3. Ex vivo autoradiograms in the brain after injection of $\left[{ }^{125} \mathrm{I}\right] \mathbf{1 8 c}$ or $\left[{ }^{125} \mathrm{I}\right] \mathbf{1 8 d}$. Anatomic atlas templates adapted from the Paxinos and Watson atlas (A), autoradiograms obtained 60 minutes after injection of $\left.{ }^{125} \mathrm{I}\right] \mathbf{1 8 c}$ (B) or $\left.{ }^{[25} \mathrm{I}\right] \mathbf{1 8 d}$ (C). Cx: cortex, Ce: cerebellum, Hip: hippocampus, Ip: interpeduncular nucleus, Tu: olfactory tubercles, St: striatum, Thal: thalamus.

Being able to penetrate the brain and to accumulate in different regions of the brain, we decided to evaluate the capacity of our ligands to target the $5-\mathrm{HT}_{4} \mathrm{R}$. A competition experiment was conducted between the specific $5-\mathrm{HT}_{4} \mathrm{R}$ radiotracer $\left[{ }^{125} \mathrm{I}\right] \mathbf{1}$ and our ligands $\mathbf{1 8 c}$-d and non radioactive 1 (Figure 4). In this in vitro study rat brain slides were first incubated with $\left[{ }^{125} \mathrm{I}\right] \mathbf{1}$ before being treated with increasing concentration of $\mathbf{1 8 c}$ and $\mathbf{1 8 d}$ (from 0.01 to $10 \mu \mathrm{M}$, Figure 4, B-F) or $1 \mu \mathrm{M}$ of 1 (Figure $4, \mathrm{G}$ ). 18c-d can inhibit the specific binding of $\left[{ }^{125} \mathrm{I}\right] \mathbf{1}$ on $5-\mathrm{HT}_{4} \mathrm{R}$ (Figure 4).

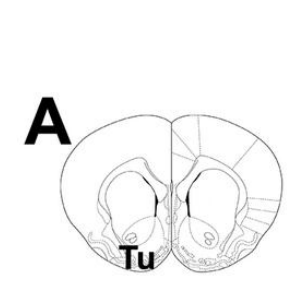

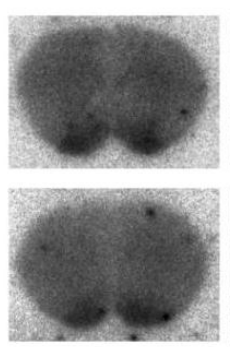

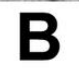

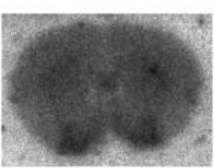
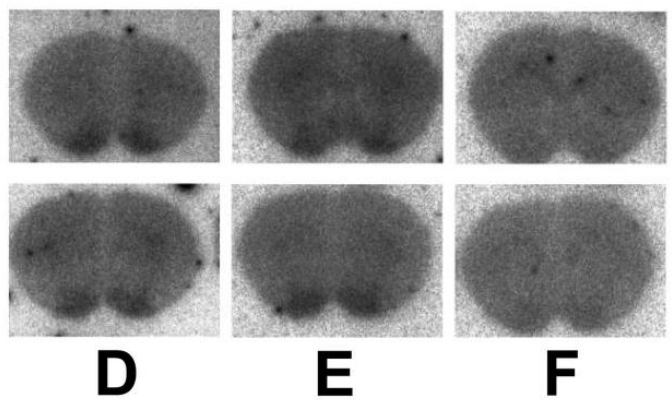

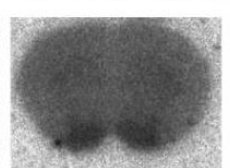

E

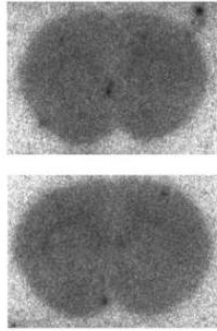

G

Figure 4. In vitro competition between $\left[{ }^{125} I\right] 1$ and $18 \mathrm{c}, 18 \mathrm{~d}$ or 1 . Localisation of olfactory tubercles (Tu) is shown in a coronal slice, adapted from the Paxinos and Watson atlas (A). Representative autoradiograms obtained by incubation of $\left[{ }^{125} \mathrm{I}\right] \mathbf{1}$ in the presence of growing concentrations $(0,0.01,0.1,1,10 \mu \mathrm{M}$, from B to $\mathrm{F}$, respectively) of 18c (topline) or 18d (line below) or in the presence of $1 \mu \mathrm{M}$ of $\mathbf{1}(\mathrm{G})$.

\section{Discussion}

Our synthetic strategy led to the development of final derivatives 18a-f, possessing an iodine atom on their structure which could be easily introduced through a late stage diversification process. Two of them were designed to possess a ketone function (18a-b) and four (18c-f) were obtained with an amide linker. Our initial objectives were to assess the influence of these pharmacomodulations on the biological activity but also on their lipophilicity and their ability to cross the BBB. All the synthesized derivatives showed moderate to good affinities for the 5- 
$\mathrm{HT}_{4} \mathrm{R}$ with low nanomolar $\mathrm{Ki}$ demonstrating that the introduction of a large iodine atom on the aromatic ring is compatible with a conserved interaction with the receptor (Table 1). We could however noticed that the iodination is detrimental to $5-\mathrm{HT}_{4} \mathrm{R}$ affinity for the two ketones $\mathbf{1 8 a - b}$ $(\mathrm{Ki}=86$ and $521 \mathrm{nM}$ respectively) which were less potent ligands than their non-iodinated precursors $14 \mathbf{a}-\mathbf{b}(\mathrm{Ki}=24.7$ and $39.9 \mathrm{nM}$ respectively). On the other hand introduction of iodine on the amides 18c-f generally improves their affinities for the $5-\mathrm{HT}_{4} \mathrm{R}$ and $\mathbf{1 8 c}$ was found to be the most potent ligand with a $\mathrm{Ki}$ of $8.64 \mathrm{nM}$ (Table 1). Concerning the other pharmacomodulations, the different alkoxy chains developed did not influence the 5-HT $\mathrm{R}$ binding and the methylenecyclohexyl linker was found superior than the propyl one (18e vs 18f). Concerning the influence of these modulations on the lipophilicity, the amide linker appears again to be the most appropriate with calculated or measured $\operatorname{LogP}$ between 3.5 and 5.2 for $\mathbf{1 8 f}$ and 18d respectively. The amide derivatives were also identified to be able to cross the BBB in a predictive PAMPA assay since all compounds $\mathbf{1 8 c}-\mathbf{f}$ could be considered as CNS + compounds. Based on this positive preliminary studies compound $18 \mathrm{c}$ and $\mathbf{1 8 d}$, the most potent compounds, were designated for the development of $\left[{ }^{125} \mathrm{I}\right]$-ligand in order to evaluate their efficiency as SPECT radiotracers.

Thus, the radioactive labeling of compounds $\mathbf{1 7 a - b}$ was performed and the resulting $\left[{ }^{125} \mathrm{I}\right] \mathbf{1 8 c}$ and $\left[{ }^{125} \mathrm{I}\right] 18 \mathrm{~d}$ were evaluated as radiotracers in vivo, ex vivo and in vitro. After injection of each radioligands in rat, in vivo SPECT imaging showed activity distribution in the brain and validated their ability to cross the $\mathrm{BBB}$. Mdr1a KO rats were used for the in vivo experiments in order to evaluate only the ability of the $\left[{ }^{125} \mathrm{I}\right] \mathbf{1 8 c}$ and $\left[{ }^{125} \mathrm{I}\right] \mathbf{1 8 d}$ tracers to specifically bind to 5 HT4R regardless of the Mdr1a expression. Autoradiograms obtained for ex vivo imaging showed an inability to obtain specific labeling in regions known to contain high densities of 5-HT 4 R. In order to address their 5-HT 4 R specific binding capacity, in vitro competition experiments with $\left[{ }^{125} \mathrm{I}\right] 1$ were performed. The selective and specific antagonist radioligand was co-administered with $18 \mathrm{c}$ and 18d. Increasing concentrations of both iodinated derivatives showed a decrease in the 5- $\mathrm{HT}_{4} \mathrm{R}$-specific radioactivity, while increasing the concentration to $10 \mu \mathrm{M}$ led to the almost complete abolishment of the signal.

\section{Conclusion}


In conclusion we have demonstrated that the modulation of the ester function of the reference 5$\mathrm{HT}_{4} \mathrm{R}$ ligands and their replacement by an amide or a ketone function do not affect the ability of the ligand to cross the blood-brain barrier. Among the synthesized derivatives, the most promising results were obtained with the amide analog $18 \mathrm{c}(\mathrm{Ki}=8.64 \mathrm{nM})$ which was able to bind to the $5-\mathrm{HT}_{4} \mathrm{R}$ in vitro as demonstrated by the displacement of $\left[{ }^{125} \mathrm{I}\right] \mathbf{1}$. However the nonspecific interactions of $\left[{ }^{125} \mathrm{I}\right] \mathbf{1 8 c}-\mathbf{d}$ with other brain regions might be explained by a fast metabolism or by their high lipophilicities which would be optimized in a future study.

\section{Experimental Section}

5.1 Chemistry. All commercially available compounds were used without further purification. Melting points were determined on a Köfler apparatus. Analytical thin-layer chromatography (TLC) was performed on silica gel $60 \mathrm{~F}_{254}$ on aluminium plates (Merck) and visualized with UV light $(254 \mathrm{~nm})$. Flash chromatography was conducted on a VWR SPOT II Essential instrument with silica gel $60(40-63 \mu \mathrm{m})$. Column's size and flow rate were used according to manufacturer's recommendation. NMR spectra were recorded at 400 or $500 \mathrm{MHz}(\mathrm{Bruker}$ Avance III 400/500 MHz) for ${ }^{1} \mathrm{H} \mathrm{NMR}$, at 100 or $125 \mathrm{MHz}$ for ${ }^{13} \mathrm{C} \mathrm{NMR}$ and at $376.1 \mathrm{MHz}$ for

${ }^{19} \mathrm{~F}$ in chloroform- $d$, methanol- $d_{4}$ or DMSO- $d_{6}$ with chemical shift $(\delta)$ given in parts per million (ppm) relative to TMS as ${ }^{1} \mathrm{H}$ and ${ }^{13} \mathrm{C}$ NMR internal standard and $\mathrm{CFCl}_{3}$ as ${ }^{19} \mathrm{~F} \mathrm{NMR}$ reference standard, and recorded at $295 \mathrm{~K}$. The following abbreviations are used to describe peak splitting patterns when appropriate: $\mathrm{br}=$ broad, $\mathrm{s}=$ singlet, $\mathrm{d}=$ doublet, $\mathrm{t}=$ triplet, $\mathrm{q}=$ quartet, $\mathrm{m}=$ multiplet, $\mathrm{dd}=$ doublet of doublet, $\mathrm{dt}=$ doublet of triplet. Coupling constants $J$ are reported in hertz units (Hz). Infrared spectra (IR) were obtained on a PERKIN-ELMER FT-IR spectrometer and are reported in terms of frequency of absorption $\left(\mathrm{cm}^{-1}\right)$ using $\mathrm{KBr}$ discs. High-resolution mass spectra (HRMS) were obtained by electronic impact (HRMS/EI), or by electrospray (HRMS/ESI) on a Bruker maXis mass spectrometer. LC-MS (ESI) analyses were realized with Waters Alliance 2695 as separating module using the following gradients: A (95\%)/B (5\%) to A $(5 \%) / \mathrm{B}(95 \%)$ in $4.00 \mathrm{~min}$. This ratio was hold during $1.50 \mathrm{~min}$ before return to initial conditions in 0.50 min. Initial conditions were then maintained for $2.00 \min \left(\mathrm{A}=\mathrm{H}_{2} \mathrm{O}, \mathrm{B}=\mathrm{CH}_{3} \mathrm{CN}\right.$; each containing $\mathrm{HCOOH}: 0.1 \%$; column XBridge C18 $2.5 \mu \mathrm{m} / 4.6 \times 50 \mathrm{~mm}$; flow rate $0.8 \mathrm{~mL} / \mathrm{min}$ ). MS were obtained on a SQ detector by positive ESI. Mass spectrum data are reported as m/z. 
Methyl 4-amino-2-hydroxybenzoate (9). To a stirred solution of 4-amino-2-hydroxybenzoic acid (2.0 g, $13.1 \mathrm{mmol}, 1.0$ eq.) in $\mathrm{MeOH}(40 \mathrm{~mL})$ was added dropwise concentrated aqueous solution of $\mathrm{H}_{2} \mathrm{SO}_{4}(2.8 \mathrm{~mL})$ and the resulting mixture was refluxed for $16 \mathrm{~h}$. After cooling to room temperature, it was neutralized with saturated aqueous $\mathrm{NaHCO}_{3}$ solution until no further gas evolution was observed and the mixture was concentrated in vacuo. The residue was dissolved in water and extracted several times with EtOAc. The combined organic extracts were dried over $\mathrm{MgSO}_{4}$ and concentrated under reduced pressure to afford (9), as a brown solid (1.97 g, 90\% yield); mp $113{ }^{\circ} \mathrm{C}$ (litt.: $115{ }^{\circ} \mathrm{C}$ [30]); ${ }^{1} \mathrm{H}$ NMR $\left(\mathrm{CDCl}_{3}, 400 \mathrm{MHz}\right) \delta 10.95$ (br s, $1 \mathrm{H}$, $\mathrm{OH}), 7.60\left(\mathrm{~d},{ }^{3} \mathrm{~J}=8.9 \mathrm{~Hz}, 1 \mathrm{H}\right), 6.14(\mathrm{~m}, 2 \mathrm{H}), 4.15\left(\mathrm{br} \mathrm{s}, 2 \mathrm{H}, \mathrm{NH}_{2}\right), 3.86(\mathrm{~s}, 3 \mathrm{H}) ;{ }^{13} \mathrm{C}$ NMR $\left(\mathrm{CDCl}_{3}, 100 \mathrm{MHz}\right) \delta 170.6,163.6,153.5,131.7,106.9,103.0,100.7,51.8$; IR (neat, $\left.\mathrm{cm}^{-1}\right) v$ $3475,3381,3249,3025,2952,2851,1642,1437,1356,1283,780 ; \mathrm{MS} m / z . \mathrm{M}+\mathrm{H}]^{+} 168.17$.

Methyl 4-amino-2-ethoxybenzoate (10a). To a stirred solution of Methyl 4-amino-2hydroxybenzoate (9) (500 mg, 3.0 mmol, 1.0 eq.) in DMF (25 mL) were added $\mathrm{K}_{2} \mathrm{CO}_{3}(829 \mathrm{mg}$, $6.0 \mathrm{mmol}, 2.0$ eq.) and Iodoethane $(288 \mu \mathrm{L}, 3.6 \mathrm{mmol}, 1.2$ eq. $)$, then the resulting mixture was stirred at $70{ }^{\circ} \mathrm{C}$ overnight. After cooling to room temperature, the mixture was concentrated in vасио. The crude was dissolved with EtOAc, then the organic layer was washed with brine, dried over $\mathrm{MgSO}_{4}$ and concentrated in vacuo. The crude was purified by chromatography on silica gel column (DCM/EtOAc, gradient 100:0 to 90:10) and concentrated under reduced pressure to afford (10a), as a white solid (360 mg, 61\% yield); mp $104{ }^{\circ} \mathrm{C} ;{ }^{1} \mathrm{H}$ NMR $\left(\mathrm{CDCl}_{3}, 400 \mathrm{MHz}\right) \delta$ $7.70\left(\mathrm{~d},{ }^{3} J=8.6 \mathrm{~Hz}, 1 \mathrm{H}\right), 6.18\left(\mathrm{dd},{ }^{3} J=8.6 \mathrm{~Hz},{ }^{4} J=2.2 \mathrm{~Hz}, 1 \mathrm{H}\right), 6.15\left(\mathrm{~d},{ }^{4} J=2.2 \mathrm{~Hz}, 1 \mathrm{H}\right), 4.13$ (br s, 2H, NH ), 3.99 (q, $\left.{ }^{3} J=7.1 \mathrm{~Hz}, 2 \mathrm{H}\right), 3.79(\mathrm{~s}, 3 \mathrm{H}), 1.42\left(\mathrm{t},{ }^{3} J=7.1 \mathrm{~Hz}, 3 \mathrm{H}\right) ;{ }^{13} \mathrm{C}$ NMR $\left(\mathrm{CDCl}_{3}, 100 \mathrm{MHz}\right) \delta 166.4,161.2,152.2,134.2,109.0,106.5,98.8,64.4,51.4,14.8$; IR (neat, $\left.\mathrm{cm}^{-1}\right) v 3500,3356,3223,2978,2947,1694,1608,1254,1038,811$; HRMS (ESI) $\mathrm{m} / z$ calcd. for $\mathrm{C}_{10} \mathrm{H}_{14} \mathrm{NO}_{3}[\mathrm{M}+\mathrm{H}]^{+}$196.0968, found 196.0965.

Methyl 4-amino-2-(2-fluoroethoxy)benzoate (10b). To a stirred solution of Methyl 4-amino-2hydroxybenzoate (9) (500 mg, $3.0 \mathrm{mmol}, 1.0$ eq.) in DMF (25 mL) were added $\mathrm{K}_{2} \mathrm{CO}_{3}(829 \mathrm{mg}$, $6.0 \mathrm{mmol}, 2.0$ eq.) and 2-fluoroethyl 4-methylbenzenesulfonate (720 mg, $3.3 \mathrm{mmol}, 1.1 \mathrm{eq}$.$) and$ the resulting mixture was stirred at $110{ }^{\circ} \mathrm{C}$ for $2 \mathrm{~h}$. After cooling to room temperature, the mixture was concentrated in vacuo. The crude was dissolved with EtOAc, then the organic layer 
was washed with brine, dried over $\mathrm{MgSO}_{4}$ and concentrated in vacuo. The crude was purified by chromatography on silica gel column (DCM/EtOAc, gradient 100:0 to 90:10) and concentrated under reduced pressure to afford (10b), as a white solid (397 mg, 62\% yield) ; mp $105{ }^{\circ} \mathrm{C} ;{ }^{1} \mathrm{H}$ NMR $\left(\mathrm{CDCl}_{3}, 400 \mathrm{MHz}\right) \delta 7.74\left(\mathrm{~d},{ }^{3} \mathrm{~J}=8.5 \mathrm{~Hz}, 1 \mathrm{H}\right), 6.28\left(\mathrm{dd},{ }^{3} J=8.5 \mathrm{~Hz},{ }^{4} \mathrm{~J}=2.2 \mathrm{~Hz}, 1 \mathrm{H}\right)$, $6.20\left(\mathrm{~d},{ }^{4} J=2.2 \mathrm{~Hz}, 1 \mathrm{H}\right), 4.78\left(\mathrm{dt},{ }^{2} J=47.4 \mathrm{~Hz},{ }^{3} J=4.2 \mathrm{~Hz}, 2 \mathrm{H}\right), 4.23\left(\mathrm{dt},{ }^{3} J=27.0 \mathrm{~Hz},{ }^{3} J=4.3\right.$ $\mathrm{Hz}, 2 \mathrm{H}), 4.07$ (br s, 2H, $\left.\mathrm{NH}_{2}\right), 3.82$ (s, 3H); ${ }^{13} \mathrm{C} \mathrm{NMR}\left(\mathrm{CDCl}_{3}, 100 \mathrm{MHz}\right) \delta 166.2,160.8,152.0$, 134.4, 110.1, 107.6, 100.3, $82.1\left(\mathrm{~d},{ }^{1} J=171.0 \mathrm{~Hz}\right), 68.8\left(\mathrm{~d},{ }^{2} J=20.7 \mathrm{~Hz}\right), 51.6 ;{ }^{19} \mathrm{~F}$ NMR $\left(\mathrm{CDCl}_{3}, 376 \mathrm{MHz}\right) \delta-223.6\left(\mathrm{tt},{ }^{2} J=47.4 \mathrm{~Hz},{ }^{3} \mathrm{~J}=27.0 \mathrm{~Hz}\right.$ ); IR (neat, $\left.\mathrm{cm}^{-1}\right) v 3497,3370,3236$, 2965, 2947, 1690, 1607, 1254, 1087, 776; HRMS (ESI) $\mathrm{m} / \mathrm{z}$ calcd. for $\mathrm{C}_{10} \mathrm{H}_{13} \mathrm{FNO}_{3}[\mathrm{M}+\mathrm{H}]^{+}$ 214.0874, found 214.0872 .

Representative procedure (d) for the synthesis of 11a-b. To a stirred solution of methyl ester derivatives (1.0 eq.) in $\mathrm{EtOH}(10 \mathrm{~mL} / \mathrm{mmol})$ was added an aqueous $1 \mathrm{~N} \mathrm{NaOH}$ solution (10.0 eq.) under nitrogen atmosphere at room temperature. The resulting mixture was stirred overnight at room temperature, and then concentrated in vacuo to remove EtOH. The residue was diluted with water. The aqueous layer was acidified by addition of hydrochloric acid until acidic $\mathrm{pH}$, and extracted several times with ethyl acetate. The combined organic extract was washed with brine, dried over $\mathrm{MgSO}_{4}$ and concentrated under reduced pressure to give the title compounds $\mathbf{1 1 a}-\mathbf{b}$.

4-amino-2-ethoxybenzoic acid (11a). The compound was prepared from Methyl 4-amino-2ethoxybenzoate (10a) (870 $\mathrm{mg}, 4.5 \mathrm{mmol}$ ) according to procedure $(d)$ and was obtained as a pale yellow solid (756 mg, 94\% yield); mp $146{ }^{\circ} \mathrm{C}$ (litt.: 152-154 ${ }^{\circ} \mathrm{C}$ [31]); ${ }^{1} \mathrm{H}$ NMR (MeOD- $d_{4}, 400$ MHz) $\delta 7.70\left(\mathrm{~d},{ }^{3} J=8.6 \mathrm{~Hz}, 1 \mathrm{H}\right), 6.33\left(\mathrm{~d},{ }^{4} \mathrm{~J}=2.0 \mathrm{~Hz}, 1 \mathrm{H}\right), 6.29\left(\mathrm{dd},{ }^{3} J=8.6 \mathrm{~Hz},{ }^{4} \mathrm{~J}=2.0 \mathrm{~Hz}\right.$, $1 \mathrm{H}), 4.21\left(\mathrm{q},{ }^{3} J=7.0 \mathrm{~Hz}, 2 \mathrm{H}\right), 1.47\left(\mathrm{t},{ }^{3} J=7.0 \mathrm{~Hz}, 3 \mathrm{H}\right) ;{ }^{13} \mathrm{C} \mathrm{NMR}\left(\mathrm{MeOD}-d_{4}, 100 \mathrm{MHz}\right) \delta$ 169.4, 161.8, 156.9, 135.5, 108.3, 106.1, 98.2, 66.1, 14.8; IR (neat, $\mathrm{cm}^{-1}$ ) v 3435, 3353, 3242, 2982, 2930, 2851, 1690, 1604, 1404, 1273, 1197, 1029; MS m/z [M+H] $]^{+} 182.42$.

4-amino-2-(2-fluoroethoxy)benzoic acid (11b). The compound was prepared from Methyl 4amino-2-(2-fluoroethoxy)benzoate (10b) $(940 \mathrm{mg}, 4.4 \mathrm{mmol})$ according to procedure $(d)$ and was obtained as a pale yellow solid (840 mg, 96\% yield); mp $124{ }^{\circ} \mathrm{C} ;{ }^{1} \mathrm{H}$ NMR (MeOD- $d_{4}, 400$ MHz) $\delta 7.70\left(\mathrm{~d},{ }^{3} \mathrm{~J}=8.4 \mathrm{~Hz}, 1 \mathrm{H}\right), 6.34-6.30(\mathrm{~m}, 2 \mathrm{H}), 4.79\left(\mathrm{dt},{ }^{2} J=47.7 \mathrm{~Hz},{ }^{3} \mathrm{~J}=4.1 \mathrm{~Hz}, 2 \mathrm{H}\right)$, 
$4.34\left(\mathrm{dt},{ }^{3} \mathrm{~J}=27.9 \mathrm{~Hz},{ }^{3} \mathrm{~J}=4.1 \mathrm{~Hz}, 2 \mathrm{H}\right) ;{ }^{13} \mathrm{C} \mathrm{NMR}\left(\mathrm{MeOD}-d_{4}, 100 \mathrm{MHz}\right) \delta 169.3,161.7,156.8$, 135.6, 108.6, 106.8, 98.8, $82.7\left(\mathrm{~d},{ }^{1} J=167.7 \mathrm{~Hz}\right), 69.8\left(\mathrm{~d},{ }^{2} J=19.8 \mathrm{~Hz}\right) ;{ }^{19} \mathrm{~F}$ NMR (MeOD- $d_{4}$, $376 \mathrm{MHz}) \delta-226.22\left(\mathrm{tt},{ }^{2} J=47.7 \mathrm{~Hz},{ }^{3} J=27.9 \mathrm{~Hz}\right.$ ); IR (neat, $\left.\mathrm{cm}^{-1}\right) v 3490,3365,3282,3240$, 2984, 2949, 1697, 1609, 1388, 1274, 1196, 1039, 884; HRMS (ESI) $m / z$ calcd. for $\mathrm{C}_{9} \mathrm{H}_{11} \mathrm{FNO}_{3}$ $[\mathrm{M}+\mathrm{H}]^{+}$200.0717, found 200.0714.

Representative procedure (e) for the synthesis of 12a-b. To a solution of benzoic acid derivatives (1.0 eq.) in dry THF (10 mL/mmol) was added CDI (1.1 eq.) and the resulting mixture was stirred at room temperature for $15 \mathrm{~h}$. Then Potassium 3-ethoxy-3-oxopropanoate (1.2 eq.) and $\mathrm{MgCl}_{2}$ (1.2 eq.) were added portion-wise. The reaction mixture was stirred at $40{ }^{\circ} \mathrm{C}$ for $24 \mathrm{~h}$. After removal of the solvent, the residue was dissolved with EtOAc, and washed with a saturated aqueous $\mathrm{NaHCO}_{3}$ solution then brine. The organic layer was dried $\left(\mathrm{MgSO}_{4}\right)$ and concentrated in vacuo. Chromatographic separation gave the title compounds.

Ethyl 3-(4-amino-2-ethoxyphenyl)-3-oxopropanoate (12a). The compound was prepared from 4-amino-2-ethoxybenzoic acid (11a) $(750 \mathrm{mg}, 4.1 \mathrm{mmol})$ according to procedure (e). After a purification by chromatography on silica gel column (cyclohexane/EtOAc, gradient 100:0 to 70:30), the compound (12a) was obtained as a white solid (233 mg, 23\% isolated yield); mp 119 ${ }^{\circ} \mathrm{C} ;{ }^{1} \mathrm{H} \mathrm{NMR}\left(\mathrm{CDCl}_{3}, 400 \mathrm{MHz}\right) \delta 7.82\left(\mathrm{~d},{ }^{3} \mathrm{~J}=8.6 \mathrm{~Hz}, 1 \mathrm{H}\right), 6.25\left(\mathrm{dd},{ }^{3} \mathrm{~J}=8.6 \mathrm{~Hz},{ }^{4} \mathrm{~J}=2.1 \mathrm{~Hz}\right.$, $1 \mathrm{H}), 6.10\left(\mathrm{~d},{ }^{4} \mathrm{~J}=2.0 \mathrm{~Hz}, 1 \mathrm{H}\right), 4.18\left(\mathrm{q},{ }^{3} \mathrm{~J}=7.1 \mathrm{~Hz}, 2 \mathrm{H}\right), 4.05\left(\mathrm{q},{ }^{3} J=7.0 \mathrm{~Hz}, 2 \mathrm{H}\right), 3.94(\mathrm{~s}, 2 \mathrm{H})$, $1.45\left(\mathrm{t},{ }^{3} \mathrm{~J}=7.0 \mathrm{~Hz}, 3 \mathrm{H}\right), 1.24\left(\mathrm{t},{ }^{3} \mathrm{~J}=7.1 \mathrm{~Hz}, 3 \mathrm{H}\right) ;{ }^{13} \mathrm{C} \mathrm{NMR}\left(\mathrm{CDCl}_{3}, 100 \mathrm{MHz}\right) \delta 190.9,169.2$, 161.3, 153.2, 133.7, 117.1, 107.4, 97.1, 64.1, 60.9, 50.7, 14.7, 14.3; IR (neat, $\mathrm{cm}^{-1}$ ) v 3477, 3381, 3244, 2977, 2938, 2889, 1720, 1594, 1457, 1338, 1204, 1017, 832; HRMS (ESI) $\mathrm{m} / z$ calcd. for $\mathrm{C}_{13} \mathrm{H}_{18} \mathrm{NO}_{4}[\mathrm{M}+\mathrm{H}]^{+}$252.1230, found 252.1227.

Ethyl 3-[4-amino-2-(2-fluoroethoxy)phenyl]-3-oxopropanoate (12b). The compound was prepared from 4-amino-2-(2-fluoroethoxy)benzoic acid (11b) $(840 \mathrm{mg}, 4.21 \mathrm{mmol})$ according to procedure (e). After a purification by chromatography on silica gel column (cyclohexane/EtOAc, gradient 100:0 to 50:50), the compound (12b) was obtained as a white solid (406 $\mathrm{mg}, 36 \%$ isolated yield); mp $117{ }^{\circ} \mathrm{C} ;{ }^{1} \mathrm{H}$ NMR $\left(\mathrm{CDCl}_{3}, 400 \mathrm{MHz}\right) \delta 7.85\left(\mathrm{~d},{ }^{3} \mathrm{~J}=8.6 \mathrm{~Hz}, 1 \mathrm{H}\right), 6.30\left(\mathrm{dd},{ }^{3} \mathrm{~J}\right.$ $\left.=8.6 \mathrm{~Hz},{ }^{4} \mathrm{~J}=2.1 \mathrm{~Hz}, 1 \mathrm{H}\right), 6.09\left(\mathrm{~d},{ }^{4} \mathrm{~J}=2.0 \mathrm{~Hz}, 1 \mathrm{H}\right), 4.79\left(\mathrm{dt},{ }^{2} J=47.3 \mathrm{~Hz},{ }^{3} J=4.1 \mathrm{~Hz}, 2 \mathrm{H}\right)$, 
$4.24\left(\mathrm{dt},{ }^{3} J=27.6 \mathrm{~Hz},{ }^{3} J=4.2 \mathrm{~Hz}, 2 \mathrm{H}\right), 4.18\left(\mathrm{q},{ }^{3} J=7.1 \mathrm{~Hz}, 2 \mathrm{H}\right), 3.96(\mathrm{~s}, 2 \mathrm{H}), 1.24\left(\mathrm{t},{ }^{3} J=7.1\right.$ $\mathrm{Hz}, 3 \mathrm{H}) ;{ }^{13} \mathrm{C} \mathrm{NMR}\left(\mathrm{CDCl}_{3}, 100 \mathrm{MHz}\right) \delta 190.8,169.1,160.5,153.2,133.8,117.2,108.1,97.3$, $81.5\left(\mathrm{~d},{ }^{1} J=170.8 \mathrm{~Hz}\right), 67.6\left(\mathrm{~d},{ }^{2} J=20.3 \mathrm{~Hz}\right), 61.0,50.6,14.2 ;{ }^{19} \mathrm{~F} \mathrm{NMR}\left(\mathrm{CDCl}_{3}, 376 \mathrm{MHz}\right) \delta-$ $223.19\left(\mathrm{tt},{ }^{2} J=47.4 \mathrm{~Hz},{ }^{3} J=27.4 \mathrm{~Hz}\right.$ ); IR (neat, $\mathrm{cm}^{-1}$ ) $v 3471,3375,3244,2990,2962,2927$, 2854, 1710, 1612, 1446, 1341, 1208, 1015, 822; HRMS (ESI) m/z calcd. for $\mathrm{C}_{13} \mathrm{H}_{17} \mathrm{FNO}_{4}$ $[\mathrm{M}+\mathrm{H}]^{+} 270.1136$, found 270.1132 .

Representatives procedures (f) and (g) for the synthesis of 13a-b. To a solution of $\beta$-keto ester derivatives (1.0 eq.) in DMF (10 mL/mmol) were added $\mathrm{K}_{2} \mathrm{CO}_{3}$ (2.0 eq.) and Tert-butyl 4(iodomethyl)piperidine-1-carboxylate (1.2 eq.). The resulting mixture was stirred at room temperature for $48 \mathrm{~h}$ then concentrated in vacuo. The residue was dissolved with EtOAc and washed with brine. The organic layer was dried $\left(\mathrm{MgSO}_{4}\right)$ and concentrated in vacuo. To a stirred solution of residue (1.0 eq.), used without any purification, in a mixture of EtOH/ $/ \mathrm{H}_{2} \mathrm{O}$ 5:1 (24 $\mathrm{mL} / \mathrm{mmol}$ ) was added $\mathrm{KOH}$ (4.5 eq.) and the resulting mixture was refluxed for $5 \mathrm{~h}$. After removal of the solvent, EtOAc was added. The organic layer was washed with brine, dried over $\mathrm{MgSO}_{4}$ and concentrated in vacuo. The residue was purified by chromatography on silica gel to give the title compounds 13a-b.

Tert-butyl 4-[3-(4-amino-2-ethoxyphenyl)-3-oxopropyl]piperidine-1-carboxylate (13a). The compound was prepared from Ethyl 3-(4-amino-2-ethoxyphenyl)-3-oxopropanoate (12a) (249 $\mathrm{mg}, 1.0 \mathrm{mmol}$ ) according to procedures $(f)$ and $(\mathrm{g})$. After a purification by chromatography on silica gel column (cyclohexane/EtOAc, gradient 100:0 to 60:40), the compound (13a) was obtained as a yellow oil (279 mg, 74\% isolated yield over 2 steps); ${ }^{1} \mathrm{H} \mathrm{NMR}\left(\mathrm{CDCl}_{3}, 400 \mathrm{MHz}\right)$ $\delta 7.69\left(\mathrm{~d},{ }^{3} J=8.5 \mathrm{~Hz}, 1 \mathrm{H}\right), 6.23\left(\mathrm{dd},{ }^{3} J=8.5 \mathrm{~Hz},{ }^{4} J=2.1 \mathrm{~Hz}, 1 \mathrm{H}\right), 6.12\left(\mathrm{~d},{ }^{4} J=2.0 \mathrm{~Hz}, 1 \mathrm{H}\right)$, $4.05(\mathrm{~m}, 4 \mathrm{H}), 2.96\left(\mathrm{t},{ }^{3} \mathrm{~J}=7.3 \mathrm{~Hz}, 2 \mathrm{H}\right), 2.66(\mathrm{~m}, 2 \mathrm{H}), 1.67-1.58(\mathrm{~m}, 4 \mathrm{H}), 1.45\left(\mathrm{t},{ }^{3} \mathrm{~J}=7.0 \mathrm{~Hz}\right.$, $3 \mathrm{H}), 1.44(\mathrm{~s}, 9 \mathrm{H}), 1.41(\mathrm{~m}, 1 \mathrm{H}), 1.10(\mathrm{~m}, 2 \mathrm{H}) ;{ }^{13} \mathrm{C} \mathrm{NMR}\left(\mathrm{CDCl}_{3}, 100 \mathrm{MHz}\right) \delta 200.1,160.7$, 155.0, 152.2, 133.2, 118.6, 107.2, 97.6, 79.3, 63.9, 44.1 (2C), 40.9, 36.0, 32.2 (2C), 31.3, 28.6 (3C), 15.0; IR (neat, $\mathrm{cm}^{-1}$ ) v 3445, 3356, 3239, 2979, 2931, 2858, 1675, 1646, 1594, 1277, 1037 , 818; HRMS (ESI) $m / z$ calcd. for $\mathrm{C}_{21} \mathrm{H}_{33} \mathrm{~N}_{2} \mathrm{O}_{4}[\mathrm{M}+\mathrm{H}]^{+} 377.2435$, found 377.2435 . 


\section{Tert-butyl 4-\{3-[4-amino-2-(2-fluoroethoxy)phenyl]-3-oxopropyl\}piperidine-1-carboxylate}

(13b). The compound was prepared from Ethyl 3-[4-amino-2-(2-fluoroethoxy)phenyl]-3oxopropanoate (12b) (400 mg, $1.49 \mathrm{mmol}$ ) according to procedures $(f)$ and $(g)$. After a purification by chromatography on silica gel column (cyclohexane/EtOAc, gradient 100:0 to 60:40), the compound (13b) was obtained as a yellow oil (414 $\mathrm{mg}, 70 \%$ isolated yield over 2 steps); mp $119{ }^{\circ} \mathrm{C} ;{ }^{1} \mathrm{H} \mathrm{NMR}\left(\mathrm{CDCl}_{3}, 400 \mathrm{MHz}\right) \delta 7.66\left(\mathrm{~d},{ }^{3} \mathrm{~J}=8.5 \mathrm{~Hz}, 1 \mathrm{H}\right), 6.23\left(\mathrm{dd},{ }^{3} \mathrm{~J}=8.5 \mathrm{~Hz}\right.$, $\left.{ }^{4} J=1.9 \mathrm{~Hz}, 1 \mathrm{H}\right), 6.08\left(\mathrm{~d},{ }^{4} J=1.9 \mathrm{~Hz}, 1 \mathrm{H}\right), 4.72\left(\mathrm{dt},{ }^{2} J=47.5 \mathrm{~Hz},{ }^{3} J=5.3 \mathrm{~Hz}, 2 \mathrm{H}\right), 4.32(\mathrm{br} \mathrm{s}$, 2H, NH$\left.)_{2}\right), 4.16\left(\mathrm{dt},{ }^{3} J=5.3 \mathrm{~Hz},{ }^{3} J=28.0 \mathrm{~Hz}, 2 \mathrm{H}\right), 4.02(\mathrm{~m}, 2 \mathrm{H}), 2.95\left(\mathrm{t},{ }^{3} J=7.4 \mathrm{~Hz}, 2 \mathrm{H}\right), 2.63$ (m, 2H), 1.65-1.55 (m, 4H), $1.41(\mathrm{~s}, 9 \mathrm{H}), 1.37(\mathrm{~m}, 1 \mathrm{H}), 1.05(\mathrm{~m}, 2 \mathrm{H}) ;{ }^{13} \mathrm{C} \mathrm{NMR}\left(\mathrm{CDCl}_{3}, 100\right.$ MHz) $\delta 199.9,160.0,154.9,152.7,133.1,118.0,107.6,97.4,81.6$ (d, ${ }^{1} J=170.9$ Hz), 79.4, 67.4 $\left(\mathrm{d},{ }^{2} J=19.7 \mathrm{~Hz}\right), 43.7(2 \mathrm{C}), 40.8,35.8,32.0(2 \mathrm{C}), 31.1,28.4(3 \mathrm{C}) ;{ }^{19} \mathrm{~F} \mathrm{NMR}\left(\mathrm{CDCl}_{3}, 376 \mathrm{MHz}\right)$ $\delta-223.28\left(\mathrm{tt},{ }^{2} J=47.5 \mathrm{~Hz},{ }^{3} J=27.8 \mathrm{~Hz}\right.$ ); IR (neat, $\mathrm{cm}^{-1}$ ) $v 3450,3355,3239,2926,2858,1677$, 1641, 1595, 1277, 1062; HRMS (ESI) $m / z$ calcd. for $\mathrm{C}_{21} \mathrm{H}_{32} \mathrm{FN}_{2} \mathrm{O}_{4}[\mathrm{M}+\mathrm{H}]^{+}$395.2341, found 395.2341.

Representatives procedures (h) and (i) for the synthesis of 14a-b. To a stirred solution of Tert-butyl piperidine-1-carboxylate derivatives (1.0 eq.) in DCM $(20 \mathrm{~mL} / \mathrm{mmol})$ was added TFA ( $2 \mathrm{~mL} / \mathrm{mmol}$ ). The resulting mixture was stirred at room temperature for $1 \mathrm{~h}$. Removal of the solvent under vacuum afforded the crude product, which was directly engaged in the next step. The residue obtained (1.0 eq.) was dissolved in DMF $(10 \mathrm{~mL} / \mathrm{mmol})$ and Bromomethylcyclohexane (1.1 eq.) and $\mathrm{K}_{2} \mathrm{CO}_{3}$ (10.0 eq.) were added. The resulting mixture was stirred at $110{ }^{\circ} \mathrm{C}$ for $5 \mathrm{~h}$, and then concentrated in vacuo. Ethyl acetate was added, the organic layer was washed several times with brine, dried over $\mathrm{MgSO}_{4}$ and concentrated in vacuo. The crude was purified by chromatography on silica gel column and concentrated under reduced pressure to afford the corresponding alkylated compounds 14a-b.

1-(4-amino-2-ethoxyphenyl)-3-[1-(cyclohexylmethyl)-4-piperidyl]propan-1-one (14a). The compound was prepared from Tert-butyl 4-[3-(4-amino-2-ethoxyphenyl)-3oxopropyl]piperidine-1-carboxylate (13a) $(280 \mathrm{mg}, 0.74 \mathrm{mmol})$ according to procedures $(h)$ and (i). After a purification by chromatography on silica gel column (cyclohexane/EtOAc, gradient 100:0 to 20:80), the compound (14a) was obtained as a yellow solid (159 mg, 58\% isolated yield 
over 2 steps); mp $84{ }^{\circ} \mathrm{C} ;{ }^{1} \mathrm{H}$ NMR $\left(\mathrm{CDCl}_{3}, 400 \mathrm{MHz}\right) \delta 7.68\left(\mathrm{~d},{ }^{3} J=8.5 \mathrm{~Hz}, 1 \mathrm{H}\right), 6.23\left(\mathrm{dd},{ }^{3} J=\right.$ $\left.8.5 \mathrm{~Hz},{ }^{4} J=2.1 \mathrm{~Hz}, 1 \mathrm{H}\right), 6.12\left(\mathrm{~d},{ }^{4} J=2.0 \mathrm{~Hz}, 1 \mathrm{H}\right), 4.09\left(\mathrm{br} \mathrm{s}, 2 \mathrm{H}, \mathrm{NH}_{2}\right), 4.05\left(\mathrm{q},{ }^{3} J=7.0 \mathrm{~Hz}\right.$, 2H), $3.02(\mathrm{~m}, 2 \mathrm{H}), 2.95\left(\mathrm{t},{ }^{3} J=7.4 \mathrm{~Hz}, 2 \mathrm{H}\right), 2.28(\mathrm{~m}, 2 \mathrm{H}), 2.07(\mathrm{~m}, 2 \mathrm{H}), 1.79-1.59(\mathrm{~m}, 9 \mathrm{H}), 1.56$ $(\mathrm{m}, 1 \mathrm{H}), 1.45\left(\mathrm{t},{ }^{3} \mathrm{~J}=7.0 \mathrm{~Hz}, 3 \mathrm{H}\right), 1.38(\mathrm{~m}, 1 \mathrm{H}), 1.27-1.08(\mathrm{~m}, 5 \mathrm{H}), 0.90(\mathrm{~m}, 2 \mathrm{H}) ;{ }^{13} \mathrm{C}$ NMR $\left(\mathrm{CDCl}_{3}, 100 \mathrm{MHz}\right) \delta 200.1,160.8,152.2,133.2,118.5,107.1,97.6,65.4,63.9,54.2$ (2C), 41.0, 35.2, 34.7, 32.1 (2C), 31.2 (2C), 31.0, 26.6, 26.1 (2C), 15.0; IR (neat, $\mathrm{cm}^{-1}$ ) v 3445, 3349, 3242, 2919, 2846, 1637, 1587, 1454, 1273, 1036, 980, 827; HRMS (ESI) $\mathrm{m} / \mathrm{z}$ calcd. for $\mathrm{C}_{23} \mathrm{H}_{37} \mathrm{~N}_{2} \mathrm{O}_{2}$ $[\mathrm{M}+\mathrm{H}]^{+}$373.2850, found 373.2850.

\section{1-[4-amino-2-(2-fluoroethoxy)phenyl]-3-[1-(cyclohexylmethyl)-4-piperidyl]propan-1-one}

(14b). The compound was prepared from Tert-butyl 4-[3-[4-amino-2-(2-fluoroethoxy)phenyl]-3oxopropyl]piperidine-1-carboxylate (13b) $(240 \mathrm{mg}, 0.61 \mathrm{mmol})$ according to procedures $(h)$ and (i). After a purification by chromatography on silica gel column (cyclohexane/EtOAc, gradient 100:0 to 20:80), the compound (14b) was obtained as a yellow solid (102 $\mathrm{mg}, 43 \%$ isolated yield over 2 steps); mp $72{ }^{\circ} \mathrm{C} ;{ }^{1} \mathrm{H}$ NMR $\left(\mathrm{CDCl}_{3}, 400 \mathrm{MHz}\right) \delta 7.70\left(\mathrm{~d},{ }^{3} J=8.5 \mathrm{~Hz}, 1 \mathrm{H}\right), 6.27\left(\mathrm{dd},{ }^{3} J=\right.$ $\left.8.5 \mathrm{~Hz},{ }^{4} J=2.0 \mathrm{~Hz}, 1 \mathrm{H}\right), 6.10\left(\mathrm{~d},{ }^{4} J=2.0 \mathrm{~Hz}, 1 \mathrm{H}\right), 4.77\left(\mathrm{dt},{ }^{2} J=47.4 \mathrm{~Hz},{ }^{3} J=4.1 \mathrm{~Hz}, 2 \mathrm{H}\right), 4.22$ $\left(\mathrm{dt},{ }^{3} \mathrm{~J}=4.1 \mathrm{~Hz},{ }^{3} \mathrm{~J}=27.6 \mathrm{~Hz}, 2 \mathrm{H}\right), 4.10\left(\mathrm{br} \mathrm{s}, 2 \mathrm{H}, \mathrm{NH}_{2}\right), 2.96\left(\mathrm{t},{ }^{3} \mathrm{~J}=7.6 \mathrm{~Hz}, 2 \mathrm{H}\right), 2.83(\mathrm{~m}, 2 \mathrm{H})$, $2.06\left(\mathrm{~d},{ }^{3} J=7.0 \mathrm{~Hz}, 2 \mathrm{H}\right), 1.82-1.57(\mathrm{~m}, 11 \mathrm{H}), 1.46(\mathrm{~m}, 1 \mathrm{H}), 1.27-1.08(\mathrm{~m}, 6 \mathrm{H}), 0.84(\mathrm{~m}, 2 \mathrm{H})$; ${ }^{13} \mathrm{C} \mathrm{NMR}\left(\mathrm{CDCl}_{3}, 100 \mathrm{MHz}\right) \delta 200.3,160.0,152.1,133.3,118.9,107.8,97.8,81.7\left(\mathrm{~d},{ }^{1} J=171.2\right.$ $\mathrm{Hz}), 67.5\left(\mathrm{~d},{ }^{2} J=20.2 \mathrm{~Hz}\right), 66.4,54.7$ (2C), 41.3, 36.0, 35.4, 32.5 (2C), 32.3 (2C), 31.4, 26.9, $26.4(2 \mathrm{C}) ;{ }^{19} \mathrm{~F}$ NMR $\left(\mathrm{CDCl}_{3}, 376 \mathrm{MHz}\right) \delta-223.3\left(\mathrm{tt},{ }^{2} J=47.1 \mathrm{~Hz},{ }^{3} J=27.8 \mathrm{~Hz}\right) ; \mathrm{IR}$ (neat, $\mathrm{cm}^{-1}$ ) $v$ 3429, 3347, 3240, 2921, 2849-2768, 1637, 1591, 1443, 1274; HRMS (ESI) m/z calcd. for $\mathrm{C}_{23} \mathrm{H}_{36} \mathrm{FN}_{2} \mathrm{O}_{2}[\mathrm{M}+\mathrm{H}]^{+} 391.2755$, found 391.2755 .

Representative procedure (j) for the synthesis of 15a-b. To a stirred solution of piperidine-4carboxamide (1.0 eq.) in EtOH ( $2 \mathrm{~mL} / \mathrm{mmol})$ were added $\mathrm{K}_{2} \mathrm{CO}_{3}$ (2.0 eq.) and alkyl-halogenated compound (1.1-1.25 eq.) and the resulting mixture was refluxed for 15-24 h. After cooling to room temperature, the mixture was concentrated in vacuo. The crude was dissolved with $\mathrm{CHCl}_{3}$, then the organic layer was washed with brine, dried over $\mathrm{MgSO}_{4}$ and concentrated in vacuo. The residue obtained was precipitated with petroleum ether and filtered to afford alkylated compound (92-93\% yields). 
1-propylpiperidine-4-carboxamide (15a). The compound was prepared from Piperidine-4carboxamide (6.0 g, $46.8 \mathrm{mmol})$ and 1-iodopropane (9.94 g, $58.5 \mathrm{mmol})$ according to procedure (j), with a reflux for $15 \mathrm{~h}$, and was obtained as a white solid $\left(7.4 \mathrm{~g}, 92 \%\right.$ yield); mp $162{ }^{\circ} \mathrm{C} ;{ }^{1} \mathrm{H}$ NMR $\left(\mathrm{CDCl}_{3}, 400 \mathrm{MHz}\right) \delta 5.49\left(\mathrm{br} \mathrm{s}, 2 \mathrm{H}, \mathrm{NH}_{2}\right), 2.97$ (m, 2H), 2.29-2.25 (m, 2H), 2.19-2.11 (m, 1H), $1.96-1.88(\mathrm{~m}, 4 \mathrm{H}), 1.80-1.68(\mathrm{~m}, 2 \mathrm{H}), 1.54-1.45(\mathrm{~m}, 2 \mathrm{H}), 0.89\left(\mathrm{t},{ }^{3} \mathrm{~J}=7.4 \mathrm{~Hz}, 3 \mathrm{H}\right) ;{ }^{13} \mathrm{C}$ NMR $\left(\mathrm{CDCl}_{3}, 100 \mathrm{MHz}\right) \delta 177.4,61.0,53.4$ (2C), 43.1, 29.2 (2C), 20.3, 12.1; IR (neat, $\left.\mathrm{cm}^{-1}\right) v$ 3382, 3194, 2953, 2931, 2872, 2809-2680, 1653, 1425, 1143, 675; HRMS (ESI) $\mathrm{m} / z$ calcd. for $\mathrm{C}_{9} \mathrm{H}_{19} \mathrm{~N}_{2} \mathrm{O}[\mathrm{M}+\mathrm{H}]^{+}$171.1492, found 171.1489.

1-(cyclohexylmethyl)piperidine-4-carboxamide (15b). The compound was prepared from Piperidine-4-carboxamide (2.92 g, $22.8 \mathrm{mmol})$ and Bromomethylcyclohexane (4.44 g, 25.1 mmol) according to procedure (j), with a reflux for $24 \mathrm{~h}$, and was obtained as white crystals (4.77 g, 93\% yield); mp $178{ }^{\circ} \mathrm{C} ;{ }^{1} \mathrm{H}$ NMR $\left(\mathrm{CDCl}_{3}, 500 \mathrm{MHz}\right) \delta 2.89(\mathrm{~m}, 2 \mathrm{H}), 2.09(\mathrm{~m}, 1 \mathrm{H}), 2.08$ $\left(\mathrm{d},{ }^{3} \mathrm{~J}=7.1 \mathrm{~Hz}, 2 \mathrm{H}\right), 1.91-1.83(\mathrm{~m}, 4 \mathrm{H}), 1.76-1.64(\mathrm{~m}, 7 \mathrm{H}), 1.46(\mathrm{~m}, 1 \mathrm{H}), 1.24-1.10(\mathrm{~m}, 3 \mathrm{H})$, $0.84(\mathrm{~m}, 2 \mathrm{H}) ;{ }^{13} \mathrm{C} \mathrm{NMR}\left(\mathrm{CDCl}_{3}, 126 \mathrm{MHz}\right) \delta$ 118.0, 66.0, 53.8 (2C), 43.2, 35.3, 32.1 (2C), 29.1 (2C), 26.9, 26.3 (2C); IR (neat, $\mathrm{cm}^{-1}$ ) v 3387, 3184, 2939, 2922, 2850, 1648, 1455, 1448, 1126, 635; HRMS (ESI) $m / z$ calcd. for $\mathrm{C}_{13} \mathrm{H}_{25} \mathrm{~N}_{2} \mathrm{O}[\mathrm{M}+\mathrm{H}]^{+} 225.1961$, found 225.1959 .

Representative procedure $(\mathbf{k})$ for the synthesis of 16a-b. To a stirred solution of alkylated piperidine-4-carboxamide (1.0 eq.) in anhydrous $\mathrm{THF}(5 \mathrm{~mL} / \mathrm{mmol})$ at $0{ }^{\circ} \mathrm{C}$ under nitrogen atmosphere was carefully added $\mathrm{LiAlH}_{4}$ (3.0 eq.). The resulting mixture was stirred at room temperature for $1-2 \mathrm{~h}$ and then refluxed for $3 \mathrm{~h}$. The reaction was then slowly quenched at $0{ }^{\circ} \mathrm{C}$ with $n \mathrm{~mL}$ of water ( $n \mathrm{~mL}$ for $n$ grams of $\mathrm{LiAlH}_{4}$ used), $n \mathrm{~mL}$ of an aqueous $15 \% \mathrm{NaOH}$ solution followed by $3 n \mathrm{~mL}$ of water to afford a granular inorganic precipitate. The solution was filtered over a pad of celite, the solid was rinsed with diethyl ether and EtOAc, then the filtrate was concentrated under reduced pressure to give reduced compound (71-96\% yields).

(1-propyl-4-piperidyl)methanamine (16a). The compound was prepared from 1-propyl piperidine-4-carboxamide (15a) $(0.2 \mathrm{~g}, 1.17 \mathrm{mmol})$ according to procedure $(k)$, with a stirring at room temperature for $1 \mathrm{~h}$ and a reflux for $3 \mathrm{~h}$, and was obtained as a yellow oil $(0.13 \mathrm{~g}, 71 \%$ 
yield); ${ }^{1} \mathrm{H} \mathrm{NMR}\left(\mathrm{CDCl}_{3}, 400 \mathrm{MHz}\right) \delta 2.93(\mathrm{~m}, 2 \mathrm{H}), 2.55\left(\mathrm{~d},{ }^{3} \mathrm{~J}=5.9 \mathrm{~Hz}, 2 \mathrm{H}\right), 2.25(\mathrm{~m}, 2 \mathrm{H})$, 1.90-1.83 (m, 2H), 1.70-1.44 (m, 5H), 1.23-1.17 (m, 2H), $0.86\left(\mathrm{t},{ }^{3} J=7.3 \mathrm{~Hz}, 3 \mathrm{H}\right)$; ${ }^{13} \mathrm{C}$ NMR $\left(\mathrm{CDCl}_{3}, 126 \mathrm{MHz}\right) \delta 61.2,53.8(2 \mathrm{C}), 48.2,39.5,30.0(2 \mathrm{C}), 20.3,12.9$; IR (neat, $\left.\mathrm{cm}^{-1}\right) v 3378$, 2956, 2930, 2874-2735, 1539, 1482, 1309, 1141.

[1-(cyclohexylmethyl)-4-piperidyl]methanamine (16b). The compound was prepared from 1(cyclohexylmethyl)piperidine-4-carboxamide (15b) (3.0 g, $13.4 \mathrm{mmol}$ ) according to procedure $(k)$, with a stirring at room temperature for $2 \mathrm{~h}$ and a reflux for $3 \mathrm{~h}$, and was obtained as a white solid (2.70 g, 96\% yield); mp $83{ }^{\circ} \mathrm{C} ;{ }^{1} \mathrm{H} \mathrm{NMR}\left(\mathrm{CDCl}_{3}, 500 \mathrm{MHz}\right) \delta 2.91$ (br s, $\left.2 \mathrm{H}, \mathrm{NH}_{2}\right), 2.85$ (m, 2H), $2.56\left(\mathrm{~d},{ }^{3} J=6.4 \mathrm{~Hz}, 2 \mathrm{H}\right), 2.07\left(\mathrm{~d},{ }^{3} J=7.0 \mathrm{~Hz}, 2 \mathrm{H}\right), 1.81(\mathrm{~m}, 2 \mathrm{H}), 1.72(\mathrm{~m}, 2 \mathrm{H}), 1.69-$ $1.61(\mathrm{~m}, 5 \mathrm{H}), 1.45(\mathrm{~m}, 1 \mathrm{H}), 1.30-1.26(\mathrm{~m}, 1 \mathrm{H}), 1.25-1.08(\mathrm{~m}, 5 \mathrm{H}), 0.83(\mathrm{~m}, 2 \mathrm{H})$; ${ }^{13} \mathrm{C}$ NMR $\left(\mathrm{CDCl}_{3}, 126 \mathrm{MHz}\right) \delta 66.3,54.3$ (2C), 47.7, 38.9, 35.3, 32.2 (2C), 29.9 (2C), 26.9, 26.3 (2C); IR $\left(\right.$ neat, $\left.\mathrm{cm}^{-1}\right) v$ 3400, 3272, 2920, 2850, 1535, 1481, 1300, 1130; HRMS (ESI) $\mathrm{m} / z$ calcd. for $\mathrm{C}_{13} \mathrm{H}_{27} \mathrm{~N}_{2}[\mathrm{M}+\mathrm{H}]^{+}$211.2169, found 211.2169.

Representative procedure (1) for the synthesis of 17a-d. To a stirred solution of acid derivative (1.0 eq.) in DMF (5 mL/mmol) were added $\mathrm{Et}_{3} \mathrm{~N}$ (1.0 eq.), EDC (1.0 eq.), HOBt (1.0 eq.) and amine derivatives (1.0 eq.) under nitrogen atmosphere and the resulting mixture was stirred at room temperature for 18-72 $\mathrm{h}$. After evaporation in vacuo to remove DMF, the residue was purified by chromatography on silica gel column and concentrated under reduced pressure to afford expected amide derivative (25-44\% isolated yields).

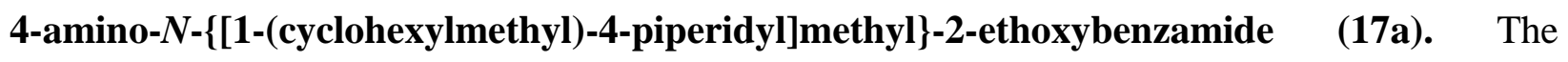
compound was prepared from [1-(cyclohexylmethyl)-4-piperidyl]methanamine (16b) (221 mg, $1.05 \mathrm{mmol}$ ) and 4-amino-2-ethoxybenzoic acid (11a) (190 mg, $1.05 \mathrm{mmol}$ ) according to procedure (l) with a stirring at room temperature for $72 \mathrm{~h}$. After a purification by flash chromatography on silica gel column (DCM/EtOAc, gradient 100:0 to 90:10), the compound (17a) was obtained as a yellow oil $\left(110 \mathrm{mg}, 28 \%\right.$ isolated yield); ${ }^{1} \mathrm{H} \mathrm{NMR}\left(\mathrm{CDCl}_{3}, 500 \mathrm{MHz}\right) \delta$ $8.01\left(\mathrm{~d},{ }^{3} J=8.5 \mathrm{~Hz}, 1 \mathrm{H}\right), 7.95(\mathrm{br} \mathrm{s}, 1 \mathrm{H}, \mathrm{NH}), 6.31\left(\mathrm{dd},{ }^{3} J=8.5 \mathrm{~Hz},{ }^{4} J=1.5 \mathrm{~Hz}, 1 \mathrm{H}\right), 6.16\left(\mathrm{~d},{ }^{4} J\right.$ $=1.6 \mathrm{~Hz}, 1 \mathrm{H}), 4.09\left(\mathrm{q},{ }^{3} \mathrm{~J}=7.0 \mathrm{~Hz}, 2 \mathrm{H}\right), 3.99\left(\mathrm{br} \mathrm{s}, 2 \mathrm{H}, \mathrm{NH}_{2}\right), 3.31\left(\mathrm{t},{ }^{3} \mathrm{~J}=6.2 \mathrm{~Hz}, 2 \mathrm{H}\right), 2.85(\mathrm{~m}$, 2H), $2.07\left(\mathrm{~d},{ }^{3} \mathrm{~J}=7.0 \mathrm{~Hz}, 2 \mathrm{H}\right), 1.83(\mathrm{~m}, 2 \mathrm{H}), 1.75-1.63(\mathrm{~m}, 7 \mathrm{H}), 1.55(\mathrm{~m}, 1 \mathrm{H}), 1.48\left(\mathrm{t},{ }^{3} J=6.9\right.$ 
$\mathrm{Hz}, 3 \mathrm{H}), 1.45(\mathrm{~m}, 1 \mathrm{H}), 1.34-1.29(\mathrm{~m}, 2 \mathrm{H}), 1.24-1.10(\mathrm{~m}, 3 \mathrm{H}), 0.84(\mathrm{~m}, 2 \mathrm{H}) ;{ }^{13} \mathrm{C} \mathrm{NMR}\left(\mathrm{CDCl}_{3}\right.$, $126 \mathrm{MHz}) \delta 165.7,158.6,150.9,134.0,111.9,107.7,98.1,66.2,64.4,54.2$ (2C), 45.3, 36.4, 35.4, 32.2 (2C), 30.3 (2C), 26.9, 26.3 (2C), 15.1; IR (neat, $\mathrm{cm}^{-1}$ ) v 3402, 3340, 3229, 2921, 2849, 1633, 1601, 1541, 1270, 1198, 1111, 1036; HRMS (ESI) $m / z$ calcd. for $\mathrm{C}_{22} \mathrm{H}_{36} \mathrm{~N}_{3} \mathrm{O}_{2}[\mathrm{M}+\mathrm{H}]^{+}$ 374.2802, found 374.2802 .

\section{4-amino- $N$-\{[1-(cyclohexylmethyl)piperidin-4-yl]methyl\}-2-(2-fluoroethoxy)benzamide}

(17b). The compound was prepared from [1-(cyclohexylmethyl)-4-piperidyl]methanamine (16b) (242 mg, $1.15 \mathrm{mmol}$ ) and 4-amino-2-(2-fluoroethoxy)benzoic acid (11b) (230 mg, $1.15 \mathrm{mmol})$ according to procedure $(l)$ with a stirring at room temperature for $48 \mathrm{~h}$. After a purification by flash chromatography on silica gel column (DCM/EtOAc, gradient 100:0 to 90:10), the compound (17b) was obtained as a yellow oil (200 mg, 44\% isolated yield); ${ }^{1} \mathrm{H} \mathrm{NMR}\left(\mathrm{CDCl}_{3}\right.$, $500 \mathrm{MHz}) \delta 8.03\left(\mathrm{~d},{ }^{3} J=8.5 \mathrm{~Hz}, 1 \mathrm{H}\right), 7.79($ br s, $1 \mathrm{H}, \mathrm{NH}), 6.37\left(\mathrm{dd},{ }^{3} J=8.5 \mathrm{~Hz},{ }^{4} J=2.1 \mathrm{~Hz}\right.$,

$1 \mathrm{H}), 6.15\left(\mathrm{~d},{ }^{4} J=2.1 \mathrm{~Hz}, 1 \mathrm{H}\right), 4.80\left(\mathrm{dt},{ }^{2} J=47.4 \mathrm{~Hz},{ }^{3} J=4.0 \mathrm{~Hz}, 2 \mathrm{H}\right), 4.28\left(\mathrm{dt},{ }^{3} J=27.4 \mathrm{~Hz},{ }^{3} J\right.$ $=4.1 \mathrm{~Hz}, 2 \mathrm{H}), 3.96\left(\right.$ br s, $\left.2 \mathrm{H}, \mathrm{NH}_{2}\right), 3.32\left(\mathrm{t},{ }^{3} \mathrm{~J}=6.5 \mathrm{~Hz}, 2 \mathrm{H}\right), 2.86(\mathrm{~m}, 2 \mathrm{H}), 2.08\left(\mathrm{~d},{ }^{3} \mathrm{~J}=7.1 \mathrm{~Hz}\right.$, $2 \mathrm{H}), 1.84(\mathrm{~m}, 2 \mathrm{H}), 1.75-1.63(\mathrm{~m}, 7 \mathrm{H}), 1.56(\mathrm{~m}, 1 \mathrm{H}), 1.47(\mathrm{~m}, 1 \mathrm{H}), 1.33(\mathrm{~m}, 2 \mathrm{H}), 1.25-1.12(\mathrm{~m}$, $3 \mathrm{H}), 0.84(\mathrm{~m}, 2 \mathrm{H}) ;{ }^{13} \mathrm{C} \mathrm{NMR}\left(\mathrm{CDCl}_{3}, 126 \mathrm{MHz}\right) \delta 165.4,157.8,150.7,134.3,112.7,108.5,98.3$, $81.5\left(\mathrm{~d},{ }^{1} J=172.1 \mathrm{~Hz}\right), 67.8\left(\mathrm{~d},{ }^{2} J=19.3 \mathrm{~Hz}\right), 66.3,54.3(2 \mathrm{C}), 45.5,36.3,35.4,32.2(2 \mathrm{C}), 30.3$ (2C), 27.0, $26.4(2 \mathrm{C}) ;{ }^{19} \mathrm{~F} \mathrm{NMR}\left(\mathrm{CDCl}_{3}, 376 \mathrm{MHz}\right) \delta-224.4\left(\mathrm{tt},{ }^{2} J=47.3 \mathrm{~Hz},{ }^{3} J=27.3 \mathrm{~Hz}\right)$; IR $\left(\right.$ neat, $\left.\mathrm{cm}^{-1}\right) v 3411,3340,3222,2921,2850,1635,1602,1541,1283,1120,1065,889$; HRMS (ESI) $m / z$ calcd. for $\mathrm{C}_{22} \mathrm{H}_{35} \mathrm{FN}_{3} \mathrm{O}_{2}[\mathrm{M}+\mathrm{H}]^{+} 392.2708$, found 392.2708.

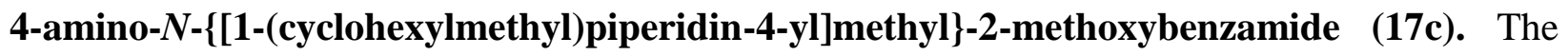
compound was prepared from [1-(cyclohexylmethyl)-4-piperidyl]methanamine (16b) (975 mg, $4.63 \mathrm{mmol}$ ) and commercial 4-amino-2-methoxybenzoic acid (11c) (774 mg, $4.63 \mathrm{mmol}$ ) according to procedure $(l)$ with a stirring at room temperature for $48 \mathrm{~h}$. After a purification by flash chromatography on silica gel column (gradient: DCM to DCM/EtOAc 90:10), the compound (17c) was obtained as a white powder (280 mg, 17\% isolated yield); ${ }^{1} \mathrm{H}$ NMR $\left(\mathrm{CDCl}_{3}, 500 \mathrm{MHz}\right) \delta 8.02\left(\mathrm{~d},{ }^{3} J=8.5 \mathrm{~Hz}, 1 \mathrm{H}\right), 7.79($ br s, $1 \mathrm{H}, \mathrm{NH}), 6.34\left(\mathrm{dd},{ }^{3} J=8.5 \mathrm{~Hz},{ }^{4} J=\right.$ $2.1 \mathrm{~Hz}, 1 \mathrm{H}), 6.20\left(\mathrm{~d},{ }^{4} \mathrm{~J}=2.1 \mathrm{~Hz}, 1 \mathrm{H}\right), 3.98\left(\right.$ br s, $\left.2 \mathrm{H}, \mathrm{NH}_{2}\right), 3.90(\mathrm{~s}, 3 \mathrm{H}), 3.31\left(\mathrm{t},{ }^{3} \mathrm{~J}=6.3 \mathrm{~Hz}\right.$, 2H), $2.87(\mathrm{~m}, 2 \mathrm{H}), 2.10\left(\mathrm{~d},{ }^{3} \mathrm{~J}=7.0 \mathrm{~Hz}, 2 \mathrm{H}\right), 1.86(\mathrm{~m}, 2 \mathrm{H}), 1.76-1.64(\mathrm{~m}, 7 \mathrm{H}), 1.58(\mathrm{~m}, 1 \mathrm{H}), 1.47$ 
$(\mathrm{m}, 1 \mathrm{H}), 1.34(\mathrm{~m}, 2 \mathrm{H}), 1.25-1.10(\mathrm{~m}, 3 \mathrm{H}), 0.85(\mathrm{~m}, 2 \mathrm{H}) ;{ }^{13} \mathrm{C} \mathrm{NMR}\left(\mathrm{CDCl}_{3}, 126 \mathrm{MHz}\right) \delta 165.6$, 159.2, 150.9, 134.1, 112.1, 107.8, 97.4, 66.2, 55.9, 54.2 (2C), 45.3, 36.4, 35.4, 32.2 (2C), 30.2 (2C), 26.9, 26.3 (2C); IR (neat, $\mathrm{cm}^{-1}$ ) v 3408, 3342, 3224, 2921, 2849, 1638, 1601, 1538, 1505, 1281, 1208; HRMS (ESI) $m / z$ calcd. for $\mathrm{C}_{21} \mathrm{H}_{34} \mathrm{~N}_{3} \mathrm{O}_{2}[\mathrm{M}+\mathrm{H}]^{+} 360.2646$, found 360.2644.

4-amino-2-methoxy- $N$-[(1-propyl-4-piperidyl)methyl]benzamide (17d). The compound was prepared from (1-propyl-4-piperidyl)methanamine (16a) (562 mg, $3.60 \mathrm{mmol}$ ) and commercial 4-amino-2-methoxybenzoic acid (11c) $(600 \mathrm{mg}, 3.60 \mathrm{mmol})$ according to procedure $(l)$ with a stirring at room temperature for $18 \mathrm{~h}$. After a first purification by chromatography on silica gel column (DCM/EtOAc, gradient 100:0 to 90:10), the crude was finally purified by C18 reversed phase column $\left(\mathrm{H}_{2} \mathrm{O} / \mathrm{ACN}\right.$, gradient 100:0 to 90:10) to separate expected product and side product of peptide coupling (similar polarity on silica gel), and concentrated under reduced pressure to afford the compound (17d) as a white solid (275 mg, 25\% isolated yield); mp $134{ }^{\circ} \mathrm{C} ;{ }^{1} \mathrm{H}$ NMR $\left(\mathrm{MeOD}-d_{4}, 500 \mathrm{MHz}\right) \delta 7.71\left(\mathrm{~d},{ }^{3} J=8.5 \mathrm{~Hz}, 1 \mathrm{H}\right), 6.35\left(\mathrm{~d},{ }^{4} J=2.0 \mathrm{~Hz}, 1 \mathrm{H}\right), 6.30\left(\mathrm{dd},{ }^{3} J=8.5\right.$ $\left.\mathrm{Hz},{ }^{4} J=2.0 \mathrm{~Hz}, 1 \mathrm{H}\right), 3.91(\mathrm{~s}, 3 \mathrm{H}), 3.55$ (m, 2H), $3.36(\mathrm{~m}, 2 \mathrm{H}), 3.00$ (m, 2H), 2.96 (m, 2H), 1.99 $(\mathrm{m}, 2 \mathrm{H}), 1.93(\mathrm{~m}, 1 \mathrm{H}), 1.75(\mathrm{~m}, 2 \mathrm{H}), 1.55(\mathrm{~m}, 2 \mathrm{H}), 1.01\left(\mathrm{t},{ }^{3} \mathrm{~J}=7.4 \mathrm{~Hz}, 3 \mathrm{H}\right) ;{ }^{13} \mathrm{C}$ NMR (MeOD$\left.d_{4}, 126 \mathrm{MHz}\right) \delta 168.9,161.1,155.2,133.9,110.1,107.9,97.6,59.6,56.2,53.5$ (2C), 44.7, 35.5, 28.3 (2C), 18.7, 11.2; IR (neat, $\mathrm{cm}^{-1}$ ) v 3394, 3210, 2937, 2655, 2534, 1624, 1600, 1543, 1505, 1282, 1210; HRMS (ESI) $m / z$ calcd. for $\mathrm{C}_{17} \mathrm{H}_{28} \mathrm{~N}_{3} \mathrm{O}_{2}[\mathrm{M}+\mathrm{H}]^{+} 306.2176$, found 306.2173.

\section{Representative procedure $(\mathrm{m})$ for iodination with standard conditions of radiolabeling. To} a stirred solution of amide derivative (1.0 eq.) in peracetic acid (acetic acid/30\% $\mathrm{H}_{2} \mathrm{O}_{2} 2: 1,50$ $\mathrm{mL} / \mathrm{mmol}$ ) was added $\mathrm{NaI}$ (1.1 eq.) (typical brown iodine color was observed) and the resulting mixture was stirred at room temperature for $1-2 \mathrm{~h}$. The reaction was cooled at $0{ }^{\circ} \mathrm{C}$ in an icewater bath, and were added respectively water and a saturated aqueous $\mathrm{Na}_{2} \mathrm{~S}_{2} \mathrm{O}_{3}$ solution. The mixture was then neutralized by addition of an aqueous $2 \mathrm{~N} \mathrm{NaOH}$ solution until basic $\mathrm{pH}(\sim 10)$, and extracted several times with DCM. The combined organic extract was dried over $\mathrm{MgSO}_{4}$ and was concentrated in vacuo. The residue was purified by chromatography on silica gel column and concentrated under reduced pressure to afford iodinated compound (18-71\% isolated yields). 


\section{1-(4-amino-2-ethoxy-5-iodophenyl)-3-[1-(cyclohexylmethyl)-4-piperidyl]propan-1-one}

(18a). The compound was prepared from 1-(4-amino-2-ethoxyphenyl)-3-[1-(cyclohexylmethyl)4-piperidyl]propan-1-one (14a) (44 $\mathrm{mg}, 0.12 \mathrm{mmol}$ ) according to procedure $(\mathrm{m})$ with a stirring at room temperature for $1 \mathrm{~h}$. After a purification by flash chromatography on silica gel column (DCM/MeOH, gradient 100:0 to 95:5), the compound (18a) was obtained as a yellow solid (11 $\mathrm{mg}, 18 \%$ isolated yield); mp $98{ }^{\circ} \mathrm{C} ;{ }^{1} \mathrm{H} \mathrm{NMR}\left(\mathrm{CDCl}_{3}, 400 \mathrm{MHz}\right) \delta 8.11(\mathrm{~s}, 1 \mathrm{H}), 6.23(\mathrm{~s}, 1 \mathrm{H})$, 4.53 (br s, 2H, NH$), 4.05$ (q, $\left.{ }^{3} J=6.9 \mathrm{~Hz}, 2 \mathrm{H}\right), 3.29(\mathrm{~m}, 2 \mathrm{H}), 2.95\left(\mathrm{t},{ }^{3} J=7.2 \mathrm{~Hz}, 2 \mathrm{H}\right), 2.57(\mathrm{~m}$, 2H), $2.40(\mathrm{~m}, 2 \mathrm{H}), 1.88-1.64(\mathrm{~m}, 10 \mathrm{H}), 1.51(\mathrm{~m}, 1 \mathrm{H}), 1.46\left(\mathrm{t},{ }^{3} \mathrm{~J}=7.0 \mathrm{~Hz}, 3 \mathrm{H}\right), 1.30-1.09(\mathrm{~m}$, 5H), $1.01(\mathrm{~m}, 2 \mathrm{H}) ;{ }^{13} \mathrm{C} \mathrm{NMR}\left(\mathrm{CDCl}_{3}, 100 \mathrm{MHz}\right) \delta 198.3,160.7,151.7,142.0,120.3,97.2,73.3$, 64.7, 64.3, 54.0 (2C), 40.4, 33.9 (2C), 32.0 (2C), 29.8 (3C), 26.1, 25.9 (2C), 14.9; IR (neat, cm ${ }^{-1}$ ) $v$ 3429, 3187, 2924, 2851, 1625, 1575, 1436, 1260, 1211, 1189, 1039; HRMS (ESI) m/z calcd. for $\mathrm{C}_{23} \mathrm{H}_{36} \mathrm{IN}_{2} \mathrm{O}_{2}[\mathrm{M}+\mathrm{H}]^{+} 499.1816$, found 499.1817 .

\section{1-[4-amino-2-(2-fluoroethoxy)-5-iodophenyl]-3-[1-(cyclohexylmethyl)-4-piperidyl] propan-}

1-one (18b). The compound was prepared from 1-[4-amino-2-(2-fluoroethoxy)phenyl]-3-[1(cyclohexylmethyl)-4-piperidyl]propan-1-one (14b) $(77 \mathrm{mg}, 0.20 \mathrm{mmol})$ according to procedure $(m)$ with a stirring at room temperature for $1 \mathrm{~h}$. After a purification by flash chromatography on silica gel column (cyclohexane/EtOAc, gradient 100:0 to 20:80), the compound (18b) was obtained as a pale yellow solid (42 mg, 41\% isolated yield); mp $129{ }^{\circ} \mathrm{C} ;{ }^{1} \mathrm{H} \mathrm{NMR}\left(\mathrm{CDCl}_{3}, 400\right.$ MHz) $\delta 8.13(\mathrm{~s}, 1 \mathrm{H}), 6.21(\mathrm{~s}, 1 \mathrm{H}), 4.78\left(\mathrm{dt},{ }^{2} J=47.4 \mathrm{~Hz},{ }^{3} J=4.0 \mathrm{~Hz}, 2 \mathrm{H}\right), 4.49$ (br s, 2H, $\left.\mathrm{NH}_{2}\right)$, $4.22\left(\mathrm{dt},{ }^{3} J=4.1 \mathrm{~Hz},{ }^{3} J=27.5 \mathrm{~Hz}, 2 \mathrm{H}\right), 2.95\left(\mathrm{t},{ }^{3} J=7.6 \mathrm{~Hz}, 2 \mathrm{H}\right), 2.83(\mathrm{~m}, 2 \mathrm{H}), 2.07\left(\mathrm{~d},{ }^{3} J=7.0\right.$ $\mathrm{Hz}, 2 \mathrm{H}), 1.83-1.56(\mathrm{~m}, 11 \mathrm{H}), 1.47(\mathrm{~m}, 1 \mathrm{H}), 1.25-1.09(\mathrm{~m}, 6 \mathrm{H}), 0.85(\mathrm{~m}, 2 \mathrm{H}) ;{ }^{13} \mathrm{C} \mathrm{NMR}\left(\mathrm{CDCl}_{3}\right.$, $100 \mathrm{MHz}) \delta 199.0,159.8,151.3,142.2,120.9,97.4,81.5\left(\mathrm{~d},{ }^{1} J=171.6 \mathrm{~Hz}\right), 74.1,67.8\left(\mathrm{~d},{ }^{2} J=\right.$ $20.2 \mathrm{~Hz}), 66.4,54.7$ (2C), 41.2, 36.0, 35.4, 32.4 (2C), 32.3 (2C), 31.3, 27.0, 26.4 (2C); ${ }^{19} \mathrm{~F}$ NMR $\left(\mathrm{CDCl}_{3}, 376 \mathrm{MHz}\right) \delta-223.3\left(\mathrm{tt},{ }^{2} J=47.4 \mathrm{~Hz},{ }^{3} J=27.4 \mathrm{~Hz}\right) ; \mathrm{IR}\left(\right.$ neat, $\left.\mathrm{cm}^{-1}\right) v 3459,3320,3203$, 2920, 2845, 1637, 1569, 1430, 1214, 1071, 899; HRMS (ESI) $m / z$ calcd. for $\mathrm{C}_{23} \mathrm{H}_{35} \mathrm{FIN}_{2} \mathrm{O}_{2}$ $[\mathrm{M}+\mathrm{H}]^{+}$517.1722, found 517.1722.

\section{4-amino- $N$-\{[1-(cyclohexylmethyl)-4-piperidyl]methyl\}-2-ethoxy-5-iodobenzamide}

(18c).

The compound was prepared from 4-amino- $N$ - $\{[1$-(cyclohexylmethyl)-4-piperidyl $]$ methyl $\}-2-$ ethoxybenzamide (17a) $(50 \mathrm{mg}, 0.13 \mathrm{mmol})$ according to procedure $(\mathrm{m})$ with a stirring at room 
temperature for $1 \mathrm{~h}$. After a purification by flash chromatography on silica gel column (DCM/MeOH, gradient 100:0 to 90:10), the compound (18c) was obtained as a pale yellow solid (46 mg, 71\% isolated yield); mp $153{ }^{\circ} \mathrm{C} ;{ }^{1} \mathrm{H}$ NMR $\left(\mathrm{CDCl}_{3}, 500 \mathrm{MHz}\right) \delta 8.44(\mathrm{~s}, 1 \mathrm{H}), 7.86$ (br s, $1 \mathrm{H}, \mathrm{NH}), 6.25$ (s, $1 \mathrm{H}), 4.41\left(\mathrm{br} \mathrm{s}, 2 \mathrm{H}, \mathrm{NH}_{2}\right), 4.08\left(\mathrm{q},{ }^{3} J=7.0 \mathrm{~Hz}, 2 \mathrm{H}\right), 3.31\left(\mathrm{t},{ }^{3} J=6.2 \mathrm{~Hz}, 2 \mathrm{H}\right)$, $2.89(\mathrm{~m}, 2 \mathrm{H}), 2.10\left(\mathrm{~d},{ }^{3} \mathrm{~J}=6.9 \mathrm{~Hz}, 2 \mathrm{H}\right), 1.87(\mathrm{~m}, 2 \mathrm{H}), 1.76-1.63(\mathrm{~m}, 7 \mathrm{H}), 1.56(\mathrm{~m}, 1 \mathrm{H}), 1.48(\mathrm{t}$, $\left.{ }^{3} J=7.0 \mathrm{~Hz}, 3 \mathrm{H}\right), 1.46(\mathrm{~m}, 1 \mathrm{H}), 1.39-1.33(\mathrm{~m}, 2 \mathrm{H}), 1.25-1.10(\mathrm{~m}, 3 \mathrm{H}), 0.84(\mathrm{~m}, 2 \mathrm{H}) ;{ }^{13} \mathrm{C}$ NMR $\left(\mathrm{CDCl}_{3}, 126 \mathrm{MHz}\right) \delta 164.4,158.6,150.4,142.8,114.0,97.5,73.7,66.1,64.8,54.1$ (2C), 45.3, 36.3, 35.3, 32.2 (2C), 30.1 (2C), 26.9, 26.3 (2C), 15.0; IR (neat, $\mathrm{cm}^{-1}$ ) v 3463, 3386, 3322, 3206, 2916, 2847, 2797, 2759, 1651, 1626, 1581, 1254, 1123, 815, 577; HRMS (ESI) $\mathrm{m} / \mathrm{z}$ calcd. for $\mathrm{C}_{22} \mathrm{H}_{35} \mathrm{IN}_{3} \mathrm{O}_{2}[\mathrm{M}+\mathrm{H}]^{+} 500.1769$, found 500.1768 .

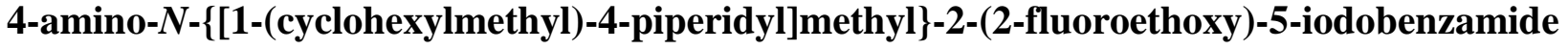

(18d). The compound was prepared from 4-amino- $N$-\{[1-(cyclohexylmethyl)-4piperidyl]methyl\}-2-(2-fluoroethoxy)benzamide (17b) (75 mg, $0.19 \mathrm{mmol}$ ) according to procedure $(m)$ with a stirring at room temperature for $1 \mathrm{~h}$. After a purification by flash chromatography on silica gel column (DCM/MeOH, gradient 100:0 to 90:10), the compound (18d) was obtained as a white solid (66 mg, 67\% isolated yield); mp $162{ }^{\circ} \mathrm{C} ;{ }^{1} \mathrm{H} \mathrm{NMR}\left(\mathrm{CDCl}_{3}\right.$, $500 \mathrm{MHz}) \delta 8.46(\mathrm{~s}, 1 \mathrm{H}), 7.70(\mathrm{br} \mathrm{s}, 1 \mathrm{H}, \mathrm{NH}), 6.23(\mathrm{~s}, 1 \mathrm{H}), 4.79\left(\mathrm{dt},{ }^{2} J=47.3 \mathrm{~Hz},{ }^{3} J=4.1 \mathrm{~Hz}\right.$, 2H), $4.44\left(\mathrm{br} \mathrm{s}, 2 \mathrm{H}, \mathrm{NH}_{2}\right), 4.25\left(\mathrm{dt},{ }^{3} J=27.2 \mathrm{~Hz},{ }^{3} J=4.1 \mathrm{~Hz}, 2 \mathrm{H}\right), 3.31\left(\mathrm{t},{ }^{3} J=6.3 \mathrm{~Hz}, 2 \mathrm{H}\right), 2.85$ (m, 2H), $2.07\left(\mathrm{~d},{ }^{3} J=7.1 \mathrm{~Hz}, 2 \mathrm{H}\right), 1.83(\mathrm{~m}, 2 \mathrm{H}), 1.75-1.63(\mathrm{~m}, 7 \mathrm{H}), 1.55(\mathrm{~m}, 1 \mathrm{H}), 1.46(\mathrm{~m}, 1 \mathrm{H})$, $1.32(\mathrm{~m}, 2 \mathrm{H}), 1.25-1.10(\mathrm{~m}, 3 \mathrm{H}), 0.85(\mathrm{~m}, 2 \mathrm{H}) ;{ }^{13} \mathrm{C} \mathrm{NMR}\left(\mathrm{CDCl}_{3}, 126 \mathrm{MHz}\right) \delta 164.1,157.8$, 150.4, 143.1, 114.5, 97.7, $81.3\left(\mathrm{~d},{ }^{1} J=172.4 \mathrm{~Hz}\right), 74.6,68.0\left(\mathrm{~d},{ }^{2} J=19.3 \mathrm{~Hz}\right), 66.3,54.2(2 \mathrm{C})$,

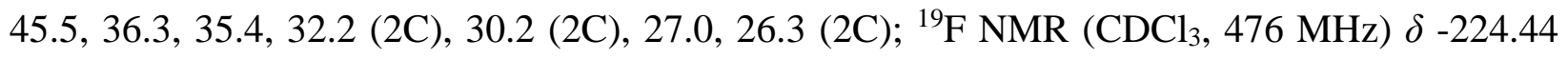
(tt, ${ }^{2} J=48.1 \mathrm{~Hz},{ }^{3} J=27.7 \mathrm{~Hz}$ ); IR (neat, $\mathrm{cm}^{-1}$ ) $v 3441,3410,3295,3181,2921,2851,1628$, 1259, 1069, 891, 596; HRMS (ESI) $\mathrm{m} / z$ calcd. for $\mathrm{C}_{22} \mathrm{H}_{34} \mathrm{FIN}_{3} \mathrm{O}_{2}[\mathrm{M}+\mathrm{H}]^{+} 518.1674$, found 518.1675 .

\section{4-amino- $N$ - $\{[1$-(cyclohexylmethyl)-4-piperidyl $]$ methyl\}-5-iodo-2-methoxybenzamide (18e).}

The compound was prepared from 4-amino- $N$-\{[1-(cyclohexylmethyl)-4-piperidyl]methyl $\}-2-$ methoxybenzamide (17c) $(200 \mathrm{mg}, 0.56 \mathrm{mmol})$ according to procedure $(\mathrm{m})$ with a stirring at room temperature for $2 \mathrm{~h}$. After a purification by flash chromatography on silica gel column 
(DCM/MeOH, gradient 100:0 to 90:10), the compound (18e) was obtained as a white solid (182 $\mathrm{mg}, 67 \%$ isolated yield); $\mathrm{mp} 174{ }^{\circ} \mathrm{C} ;{ }^{1} \mathrm{H} \mathrm{NMR}\left(\mathrm{CDCl}_{3}, 400 \mathrm{MHz}\right) \delta 8.44(\mathrm{~s}, 1 \mathrm{H}), 7.69\left(\mathrm{t},{ }^{3} \mathrm{~J}=5.5\right.$ $\mathrm{Hz}, 1 \mathrm{H}, \mathrm{NH}), 6.27$ (s, 1H), 4.44 (br s, 2H, NH 2$), 3.88$ (s, 3H), 3.30 (t, $\left.{ }^{3} \mathrm{~J}=6.2 \mathrm{~Hz}, 2 \mathrm{H}\right), 2.87$ (m, 2H), $2.09\left(\mathrm{~d},{ }^{3} \mathrm{~J}=7.0 \mathrm{~Hz}, 2 \mathrm{H}\right), 1.85(\mathrm{~m}, 2 \mathrm{H}), 1.76-1.62(\mathrm{~m}, 7 \mathrm{H}), 1.57(\mathrm{~m}, 1 \mathrm{H}), 1.47(\mathrm{~m}, 1 \mathrm{H}), 1.34$ $(\mathrm{m}, 2 \mathrm{H}), 1.27(\mathrm{~m}, 3 \mathrm{H}), 0.85(\mathrm{~m}, 2 \mathrm{H}) ;{ }^{13} \mathrm{C} \mathrm{NMR}\left(\mathrm{CDCl}_{3}, 100 \mathrm{MHz}\right) \delta 164.3,159.2,150.5,142.9$, 114.1, 96.8, 73.8, 66.1, 56.1, 54.2 (2C), 45.3, 36.4, 35.4, 32.2 (2C), 30.1 (2C), 26.9, 26.3 (2C); IR (neat, $\mathrm{cm}^{-1}$ ) v 3452, 3314, 3196, 2917, 2845, 1636, 1583, 1551, 1409, 1267, 1211; HRMS (EI) $m / z$ calcd. for $\mathrm{C}_{21} \mathrm{H}_{32} \mathrm{IN}_{3} \mathrm{O}_{2}[\mathrm{M}]^{+\cdot} 485.1540$, found 485.1537 .

\section{4-amino-5-iodo-2-methoxy- $N$-[(1-propyl-4-piperidyl)methyl]benzamide $\quad$ (18f). $\quad$ The} compound was prepared from 4-amino-2-methoxy- $N$-[(1-propyl-4-piperidyl)methyl]benzamide (17d) $(50 \mathrm{mg}, 0.16 \mathrm{mmol})$ according to procedure $(\mathrm{m})$. After a purification by chromatography on silica gel column (DCM/MeOH 90:10 to DCM/MeOH/Et3N 90:10:2), the compound (18f) was obtained as a white solid (22 mg, 32\% isolated yield); mp $114{ }^{\circ} \mathrm{C} ;{ }^{1} \mathrm{H} \mathrm{NMR}\left(\mathrm{CDCl}_{3}, 500\right.$ MHz) $\delta 8.41$ (s, 1H), 7.79 (br s, 1H, NH), 6.29 (s, 1H), 4.47 (br s, 2H, NH 2$), 3.90$ (s, 3H), 3.33 $(\mathrm{m}, 4 \mathrm{H}), 2.68(\mathrm{~m}, 2 \mathrm{H}), 2.43(\mathrm{~m}, 2 \mathrm{H}), 1.96-1.76(\mathrm{~m}, 7 \mathrm{H}), 0.95\left(\mathrm{t},{ }^{3} J=7.4 \mathrm{~Hz}, 3 \mathrm{H}\right) ;{ }^{13} \mathrm{C}$ NMR $\left(\mathrm{CDCl}_{3}, 126 \mathrm{MHz}\right) \delta 164.7,159.3,150.8,142.8,113.5,96.8,73.7,59.7,56.2,52.8(2 \mathrm{C}), 44.5$, 34.3, 27.8 (2C), 18.3, 11.6; IR (neat, $\mathrm{cm}^{-1}$ ) v 3395, 3197, 2959, 2933, 2649, 2531, 1623, 1587 , 1538, 1257, 1213; HRMS (ESI) $m / z$ calcd. for $\mathrm{C}_{17} \mathrm{H}_{27} \mathrm{IN}_{3} \mathrm{O}_{2}[\mathrm{M}+\mathrm{H}]^{+} 432.1150$, found 432.1142 .

\subsection{Synthesis of radiotracers}

Iodine-125 Radionuclide (specific activity $\sim 629 \mathrm{GBq} / \mathrm{mg}$ ) was obtained from Perkinelmer.

$\left[{ }^{125} \mathrm{I}\right] \mathbf{1 8 c}$ and $\left[{ }^{125} \mathrm{I}\right] \mathbf{1 8 d}$ were obtained by incubation, for $30 \mathrm{~min}$ at room temperature, of a mixture containing $5 \mu \mathrm{l}$ of precursor $(10 \mu \mathrm{g} / \mu \mathrm{l}$ in ethanol), $3 \mu \mathrm{l}$ of glacial acetic acid, $3 \mu \mathrm{l}$ of $30 \%$ $\mathrm{H}_{2} \mathrm{O}_{2}$ and $10 \mathrm{mCi}$ of carrier-free ${ }^{125} \mathrm{I}$ sodium iodide in $0.1 \mathrm{M}$ aqueous $\mathrm{NaOH}$. Radiotracers were isolated by a linear gradient HPLC run (from 5\% acetonitrile, $\mathrm{ACN}$, to $95 \% \mathrm{ACN}, 10 \mathrm{mM}$ aqueous $\mathrm{H}_{3} \mathrm{PO}_{4}$, in $10 \mathrm{~min}$ ).

HPLC was equipped with a reverse-phase column (Phenomenex Bonclone C18, Phenomenex, Schlieren, Switzerland) and radiotracers were eluted at a flow of $3 \mathrm{~mL} / \mathrm{min}$. Fractions containing radiotracers were diluted in water and loaded on a Sep-Pak cartridge (Sep-Pak C18, Waters, 
Switzerland). Radiotracers were eluted with $0.5 \mathrm{ml}$ of $95 \%$ ACN, $10 \mathrm{mM} \mathrm{H}_{3} \mathrm{PO}_{4}$ and concentrated using a rotary evaporator, and the final products were diluted in saline prior to animal administration.

During the HPLC run, ultraviolet absorbance and radioactivity were monitored, allowing for the measurement of specific activity thanks to calibration curves established with the cold reference compound. Radiochemical yields were $47 \%$ and $61 \%$ for $\left[{ }^{125} \mathrm{I}\right] \mathbf{1 8 c}$ and $\left[{ }^{125} \mathrm{I}\right] \mathbf{1 8 d}$, respectively. Specific activity of radiotracers was superior to $200 \mathrm{GBq} / \mu \mathrm{mol}$.

\subsection{In vivo and Ex vivo imaging experiments}

Three Sprague Dawley Mdr1a KO (SD-Abcbal ${ }^{\text {tm1sage }}$, Sigma Advance Genetic Engineering Labs, Boyertown, PA) rats $(390 \pm 22 \mathrm{~g})$ were used to determine the efficacy of $\left[{ }^{125} \mathrm{I}\right] \mathbf{1 8 c}(\mathrm{n}=1)$ and $\left[{ }^{125} \mathrm{I}\right] 18 \mathrm{~d}(\mathrm{n}=2)$ to image $5 \mathrm{HT} 4 \mathrm{R}$ in vivo. Anesthetized animals (4\% isoflurane for induction, $2.5 \%$ for maintenance) were placed in the USPECT with their head positioned in the center of the field of view. Body temperature was maintained at $37 \pm 1{ }^{\circ} \mathrm{C}$ using a thermostatically controlled heating blanket. A 60 min acquisition was initiated upon a tail vein injection of tracer $(26 \pm 2.4 \mathrm{MBq})$. Immediately after the end of the acquisition, rats were euthanized by decapitation. The brains were quickly removed and frozen in pre-cold isopentane. Transverse sections $(20 \mu \mathrm{m})$ were cut on a cryostat and exposed to phosphor imaging plates overnight (Fuji Photo Film Co., Tokyo, Japan). All experimental procedures were performed in accordance with the Swiss Federal Law on animal care under a protocol approved by the Ethical Committee on Animal Experimentation of the Canton of Geneva, Switzerland.

\subsection{In vitro competition}

Transverse sections ( $20 \mu \mathrm{m})$, from two Sprague Dawley Mdr1a KO rats, at the level of olfactory tubercles were cut on a cryostat. Slides were air-dried and stored at $-20{ }^{\circ} \mathrm{C}$. Sections were preincubated in $50 \mathrm{mM}$ Tris- $\mathrm{HCl}$ buffer $(\mathrm{pH}=7.4)$ for $15 \mathrm{~min}$. Sections were then treated with ${ }^{125} \mathrm{I}-$ SB207710 $(0.24 \mathrm{MBq} / \mathrm{ml})$ in $50 \mathrm{mM}$ Tris- $\mathrm{HCl}$ buffer $(\mathrm{pH}=7.4)$ for $90 \mathrm{~min}$ in the presence of increased 18c or 18d concentrations (from 0.01 to $10 \mu \mathrm{M}$ ) or in the presence of $1 \mu \mathrm{M}$ of SB207710. Sections were washed 3 times in ice cold buffer, dipped in ice-cold deionized water, 
and air-dried. Finally, sections were exposed to phosphor imaging plates overnight (Fuji Photo Film Co., Tokyo, Japan).

\subsection{Biological Methods}

\subsubsection{5-HT 4 binding experiment}

For radioligand binding studies, $2.5 \mu \mathrm{g}$ of proteins $\left(5-\mathrm{HT}_{4} \mathrm{~B}\right.$ membrane preparations, HTS110M, Millipore) were incubated in duplicate at $25{ }^{\circ} \mathrm{C}$ for $60 \mathrm{~min}$ in the absence or the presence of $10^{-6}$ or $10^{-8} \mathrm{M}$ of each drug and $1 \mathrm{nM}\left[{ }^{3} \mathrm{H}\right]-\mathrm{GR} 113808$ (VT 240, ViTrax) in $25 \mathrm{mM}$ Tris buffer (pH 7.4). At the end of the incubation, homogenates were filtered through Whatman $\mathrm{GF} / \mathrm{C}$ filters (Alpha Biotech) presoaked with $0.5 \%$ polyethylenimine using a Brandel cell harvester. Filters were subsequently washed three times with $4 \mathrm{~mL}$ of ice-cold $25 \mathrm{mM}$ Tris buffer (pH 7.4). Non specific binding was evaluated in parallel in the presence of $30 \mu \mathrm{M}$ serotonin.

The method was validated from saturation studies: six concentrations of $\left[{ }^{3} \mathrm{H}\right] \mathrm{GR} 113808$ were used to give final concentrations of $0.0625-2 \mathrm{nM}$, and nonspecific binding of $\left[{ }^{3} \mathrm{H}\right] \mathrm{GR} 113808$ was defined in the presence of $30 \mu \mathrm{M}$ serotonin to determine the $\mathrm{Kd}$ and the Bmax. For competition studies, $\left[{ }^{3} \mathrm{H}\right] \mathrm{GR} 113808$ was used to give a final concentration of $0.2 \mathrm{nM}$.

Percentages of inhibition of the binding of $\left[{ }^{3} \mathrm{H}\right] \mathrm{GR} 113808$ were obtained for concentrations of $10^{-6}$ and $10^{-8} \mathrm{M}$ of the ligands tested. For some of these compounds, affinity constants were calculated from five-point inhibition curves using the EBDA-Ligand software and expressed as $\mathrm{Ki} \pm \mathrm{SD}$.

\subsubsection{Lipophilicity evaluation}

Log P estimation was carried out using an isocratic liquid chromatography method for basic compounds derived from method described by Henchoz [29].

All experiments were performed on a UHPLC Agilent 1290 Infinity system (Agilent Technologies, Santa Clara, California, USA) equipped with a PDA detector 1260 operating at 220, 240, 254, 290 and $350 \mathrm{~nm}$ for all compounds. The chromatographic system was controlled by Open LAB CDS LC Chemstation ${ }^{\mathrm{TM}}$ software (revision C01.05). Retention time measurement was performed at $27{ }^{\circ} \mathrm{C}$, with a flow rate $0.6 \mathrm{~mL} \cdot \mathrm{min}^{-1}$, and by using an Acquity BEH Shield RP18 column $(1.7 \mu \mathrm{m}, 2.1$ x $50 \mathrm{~mm})$ from Waters (Milford, MA, USA). Mobile phase was 
composed by various percentage of methanol as organic modifier (35-85\%) and an aqueous basic buffer, a triethylammonium acetate solution at $\mathrm{pH} 11.5$ adjusted by sodium hydroxide addition, in order to keep calibration and newly synthesized basic compounds in their neutral form.

Briefly, Log P was estimated by plotting the known $\log \mathrm{P}$ values of 13 basic standard compounds with their $\log \mathrm{k}_{49} \%$, which is the retention factor at $49 \%$ methanol. Calculation of $\log \mathrm{k}_{49} \%$ values was performed from retention time $\left(t_{R}\right)$ measurement at three different mobile phase compositions. Each compound was injected $(1 \mu \mathrm{L})$ once with each mobile phase composition and $t_{R}$ determined from the apex of the peak. Finally, log $k_{49 \%}$ values were obtained by extrapolation to $49 \%$ organic modifier using linear relationships between $\log \mathrm{k}$ values and methanol percentage ( $\mathrm{r}^{2}>0.99$ for all compounds).

Calibration curve was built with Log $\mathrm{P}_{\text {oct }}$ values of standards obtained from literature versus their calculated $\log \mathrm{K}_{49} \%$ which is the logarithm of retention factor $\mathrm{K}$ at $49 \%$ methanol in mobile phase. Linear relationships between $\log \mathrm{P}_{\text {oct }}$ and calculated $\log \mathrm{K}_{49 \%}$ was expessed by the following equation :

$\log \mathrm{K}_{49 \%}=0.5226 \times \log \mathrm{P}_{\mathrm{oct}}-0.7058$ with $\mathrm{r}^{2}=0.978$ and $\mathrm{F}=444$

$\begin{array}{llllll}\text { Calculated } & \log \mathrm{P} & \text { were } & \text { obtained } & \text { using }\end{array}$ (http://www.chemaxon.com/products/marvin/marvinsketch/http://www.chemaxon.com/products/ marvin/marvinsketch/) or Molinspiration (http://www.molinspiration.com/cgi-bin/properties).

\subsubsection{Parallel Artificial Membrane Permeability Assay (PAMPA).}

The PAMPA-BBB experiment were conducted using the Pampa Explorer Kit (Pion Inc) according to manufacturer's protocol. Each stock compound solution (20 mM in DMSO) were diluted in Prisma HT buffer pH 7.4 (pION) to $100 \mu$ M. $200 \mu \mathrm{L}$ of this solution (n=6) was added to donor plate (P/N 110243). $5 \mu \mathrm{L}$ of the BBB-1 Lipid (P/N 110672) was used to coat the membrane filter of the acceptor plate (P/N 110243). $200 \mu \mathrm{L}$ of the Brain Sink Buffer (P/N 110674) was added to each well of the acceptor plate. The sandwiches were incubated at room temperature for $4 \mathrm{~h}$, without stirring. After incubation, the UV-visible spectra were measured with the microplate reader (Tecan infinite M200) and the $-\log P e$ were calculated for each compound by using the PAMPA Explorer software v. 3.7 (pION). Quality control standards with 
known $-\log P e$ values were used as references: the highly permeable corticosterone $(-\log P e=$ 4.6) and the low permeable theophylline $(-\log P e<6.0)$ for the PAMPA-BBB experiments, and the low/moderately permeable ketoprofen and antipyrine $(-\log \mathrm{Pe}=5.8$ at $\mathrm{pH} 7.4)$ for the PAMPA-GIT assays.

\title{
Acknowledgments
}

This work was supported by funding from the French Agence Nationale de la Recherche Project MALAD ANR-12-JS007-0012-01 and the Interreg program AI-Chem Channel. This work was also supported by the Swiss National Science Foundation (no. 310030-120369). The authors are grateful for the contribution of the "Association IFRAD Suisse", which was created in 2009 at the initiative of the "Fondation pour la Recherche sur Alzheimer" (formerly IFRAD France).

\author{
Abbreviations \\ AD Alzheimer's Disease \\ BBB blood brain barrier \\ 5-HT 5-Hydroxytryptamine, serotonin \\ $\mathrm{Ce} \quad$ cerebellum \\ CNS central nervous system \\ Cx cortex \\ Hip hippocampus \\ Ip interpeduncular nucleus \\ PET positron emission tomography \\ SPECT single photon emission computed tomography \\ St striatum \\ Thal thalamus \\ $\mathrm{Tu} \quad$ olfactory tubercles
}

\section{Supplementary information}

Supplementary data related to this article can be found at

\section{References}

[1] J.D. McCorvy, B.L. Roth, Structure and function of serotonin G protein-coupled 
receptors, Pharmacol. Ther. 150 (2015) 129-142.

[2] J.S.D. Kumar, M.J. Mann, PET Tracers for Serotonin Receptors and Their Applications, Cent. Nerv. Syst. Agents Med. Chem. 14 (2014) 92-112.

[3] L.M. Paterson, B.R. Kornum, D.J. Nutt, V.W. Pike, G.M. Knudsen, 5-HT radioligands for human brain imaging with PET and SPECT., Med. Res. Rev. 33 (2013) 54-111.

[4] A. Dumuis, R. Bouhelal, M. Sebben, R. Cory, J. Bockaert, A nonclassical 5hydroxytryptamine receptor positively coupled with adenylate cyclase in the central nervous system., Mol. Pharmacol. 34 (1988) 880-887.

[5] J. Bockaert, S. Claeysen, V. Compan, A. Dumuis, 5-HT4 receptors, a place in the sun: Act two, Curr. Opin. Pharmacol. 11 (2011) 87-93.

[6] J. Tack, M. Camilleri, L. Chang, W.D. Chey, J.J. Galligan, B.E. Lacy, S. Müller, E.M. Quigley, J. Schuurkes, J.H. De Maeyer, V. Stanghellini, Systematic review: cardiovascular safety profile of 5-HT(4) agonists developed for gastrointestinal disorders., Aliment. Pharmacol. Ther. 35 (2012) 745-767.

[7] P. Giannoni, F. Gaven, D. de Bundel, K. Baranger, E. Marchetti-Gauthier, F.S. Roman, E. Valjent, P. Marin, J. Bockaert, S. Rivera, S. Claeysen, Early administration of RS 67333, a specific 5-HT4 receptor agonist, prevents amyloidogenesis and behavioral deficits in the 5XFAD mouse model of Alzheimer's disease., Front. Aging Neurosci. 5 (2013) 96.

[8] S. Claeysen, J. Bockaert, P. Giannoni, Serotonin: A New Hope in Alzheimer's Disease?, ACS Chem. Neurosci. 6 (2015) 940-943.

[9] R. Vidal, E. Castro, F. Pilar-Cuellar, J. Pascual-Brazo, A. Diaz, M.L. Rojo, R. Linge, A. Martin, E.M. Valdizan, A. Pazos, Serotonin 5-HT4 Receptors: A New Strategy for Developing Fast Acting Antidepressants?, Curr. Pharm. Des. 20 (2014) 3751-3762.

[10] R. Bureau, M. Boulouard, F. Dauphin, F. Lezoualc'h, S. Rault, Review of 5-HT4R ligands: state of art and clinical applications., Curr. Top. Med. Chem. 10 (2010) 527-553.

[11] R.M. Pinder, R.N. Brogden, P.R. Sawyer, T.M. Speight, G.S. Avery, Metoclopramide: a review of its pharmacological properties and clinical use., Drugs. 12 (1976) 81-131.

[12] R.M. Eglen, D.W. Bonhaus, L.G. Johnson, E. Leung, R.D. Clark, Pharmacological characterization of two novel and potent 5-HT4 receptor agonists, RS 67333 and RS 67506, in vitro and in vivo., Br. J. Pharmacol. 115 (1995) 1387-1392.

[13] V.W. Pike, C. Halldin, K. Nobuhara, J. Hiltunen, R.S. Mulligan, C.-G. Swahn, P. 
Karlsson, H. Olsson, S.P. Hume, E. Hirani, J. Whalley, L.S. Pilowsky, S. Larsson, P.O. Schnell, P.J. Ell, L. Farde, Radioiodinated SB 207710 as a radioligand in vivo: imaging of brain 5-HT4 receptors with SPET., Eur. J. Nucl. Med. Mol. Imaging. 30 (2003) 15201528.

[14] B.R. Kornum, N.M. Lind, N. Gillings, L. Marner, F. Andersen, G.M. Knudsen, Evaluation of the novel 5-HT4 receptor PET ligand [11C]SB207145 in the Göttingen minipig., J. Cereb. Blood Flow Metab. 29 (2009) 186-196.

[15] M.E. Haahr, P.M. Fisher, C.G. Jensen, V.G. Frokjaer, B.M. Mahon, K. Madsen, W.F. Baare, S. Lehel, A. Norremolle, E.A. Rabiner, G.M. Knudsen, Central 5-HT4 receptor binding as biomarker of serotonergic tonus in humans: a [11C]SB207145 PET study, Mol. Psychiatry. 19 (2014) 427-432.

[16] F. Caillé, T.J. Morley, A.A.S. Tavares, C. Papin, N.M. Twardy, D. Alagille, H.S. Lee, R.M. Baldwin, J.P. Seibyl, O. Barret, G.D. Tamagnan, Synthesis and biological evaluation of positron emission tomography radiotracers targeting serotonin 4 receptors in brain: [18F]MNI-698 and [18F]MNI-699., Bioorg. Med. Chem. Lett. 23 (2013) 6243-6247.

[17] A.A.S. Tavares, F. Caillé, O. Barret, C. Papin, H. Lee, T.J. Morley, K. Fowles, D. Holden, J.P. Seibyl, D. Alagille, G.D. Tamagnan, In vivo evaluation of 18F-MNI698: an 18F-labeled radiotracer for imaging of serotonin 4 receptors in brain., J. Nucl. Med. 55 (2014) 858-864.

[18] A.A.S. Tavares, F. Caillé, O. Barret, C. Papin, H. Lee, T.J. Morley, K. Fowles, D. Holden, J.P. Seibyl, D. Alagille, G.D. Tamagnan, Whole-body biodistribution and dosimetry estimates of a novel radiotracer for imaging of serotonin 4 receptors in brain: $\left[{ }^{18}\right.$ F]MNI-698., Nucl. Med. Biol. 41 (2014) 432-439.

[19] T.G. Lohith, R. Xu, T. Tsujikawa, C.L. Morse, K.B. Anderson, R.L. Gladding, S.S. Zoghbi, M. Fujita, R.B. Innis, V.W. Pike, Evaluation in monkey of two candidate PET radioligands, [(11) C]RX-1 and [(18) F]RX-2, for imaging brain 5-HT4 receptors., Synapse, 68 (2014) 613-623.

[20] E. Dubost, N. Dumas, C. Fossey, R. Magnelli, S. Butt-Gueulle, C. Ballandonne, D.H. Caignard, F. Dulin, J. Sopkova de-Oliveira Santos, P. Millet, Y. Charnay, S. Rault, T. Cailly, F. Fabis, Synthesis and structure-affinity relationships of selective high-affinity 5HT4 receptor antagonists: Application to the design of new potential single photon 
emission computed tomography tracers, J. Med. Chem. 55 (2012) 9693-9707.

[21] N. Fresneau, N. Dumas, B.B. Tournier, C. Fossey, C. Ballandonne, A. Lesnard, P. Millet, Y. Charnay, T. Cailly, J.P. Bouillon, F. Fabis, Design of a serotonin 4 receptor radiotracer with decreased lipophilicity for single photon emission computed tomography, Eur. J. Med. Chem. 94 (2015) 386-396.

[22] C. Lecoutey, D. Hedou, T. Freret, P. Giannoni, F. Gaven, M. Since, V. Bouet, C. Ballandonne, S. Corvaisier, A. Malzert-Freon, S. Mignani, T. Cresteil, M. Boulouard, S. Claeysen, C. Rochais, P. Dallemagne, Design of donecopride, a dual serotonin subtype 4 receptor agonist/acetylcholinesterase inhibitor with potential interest for Alzheimer's disease treatment., Proc. Natl. Acad. Sci. U. S. A. 111 (2014) E3825-E3830.

[23] A.M. Catafau, M. Danus, S. Bullich, G. Nucci, J. Llop, S. Abanades, V.J. Cunningham, J.L. Eersels, J. Pavia, M. Farre, Characterization of the SPECT 5-HT 2A Receptor Ligand 123 I-R91150 in Healthy Volunteers : Part 2 - Ketanserin Displacement, J. Nucl. Med. 47 (2006) 929-937.

[24] N. Dumas, M. Moulin-Sallanon, N. Ginovart, B.B. Tournier, P. Suzanne, T. Cailly, F. Fabis, S. Rault, Y. Charnay, P. Millet, Small-animal single-photon emission computed tomographic imaging of the brain serotoninergic systems in wild-type and Mdrla knockout rats, Mol. Imaging. 13 (2014) 1-12.

[25] S.R. Donohue, K. Varnäs, Z. Jia, B. Gulyás, V.W. Pike, C. Halldin, Synthesis and in vitro autoradiographic evaluation of a novel high-affinity radioiodinated ligand for imaging brain cannabinoid subtype-1 receptors, Bioorg. Med. Chem. Lett. 19 (2009) 6209-6212.

[26] J. Mertens, D. Terriere, V. Sipido, W. Gommeren, P.M.F. Janssen, J.E. Leysen, Radiosynthesis of a new radioiodinated ligand for serotonin-5HT2-receptors, a promising tracer for $\gamma$-emission tomography, J. Label. Compd. Radiopharm. 34 (1994) 795-806.

[27] C. Rochais, C. Lecoutey, F. Gaven, P. Giannoni, K. Hamidouche, D. Hedou, E. Dubost, D. Genest, S. Yahiaoui, T. Freret, V. Bouet, F. Dauphin, J. Sopkova de-Oliveira Santos, C. Ballandonne, S. Corvaisier, A. Malzert-Freon, R. Legay, M. Boulouard, S. Claeysen, P. Dallemagne, Novel Multi-Target Directed Ligands (MTDLs) with acetylcholinesterase (AChE) inhibitory and serotonergic subtype 4 receptor (5-HT4R) agonist activities as potential agents against Alzheimer's disease: the design of donecopride, J. Med. Chem. 58 (2015) 3172-3187. 
[28] C.J. Grossman, G.J. Kilpatrick, K.T. Bunce, Development of a radioligand binding assay for 5-HT4 receptors in guinea-pig and rat brain, Br. J. Pharmacol. 109 (1993) 618-624.

[29] Y. Henchoz, D. Guillarme, S. Martel, S. Rudaz, J.-L. Veuthey, P.-A. Carrupt, Fast log P determination by ultra-high-pressure liquid chromatography coupled with UV and mass spectrometry detections., Anal. Bioanal. Chem. 394 (2009) 1919-1930.

[30] J.-Y. Park, S.-W. Kim, H.-J. Park, W.B. Im, J.-K. Lee, S.-H. Yoon, Synthesis and antioxidant effect of caffeic acid analogues bearing a carboxy and hydroxymethyl group, Bull. Korean Chem. Soc. 31 (2010) 3860-3863.

[31] B. Biasotti, S. Dallavalle, L. Merlini, C. Farina, S. Gagliardi, C. Parini, P. Belfiore, Synthesis of Photoactivable Inhibitors of Osteoclast Vacuolar ATPase, Bioorg. Med. Chem. 11 (2003) 2247-2254. 


\title{
List of Captions
}

Figure 1. A: Structures of reference 5-HT 4 R ligands; B: 5- $\mathrm{HT}_{4} \mathrm{R}$ PET and SPECT radiotracers; C: $5-\mathrm{HT}_{2 \mathrm{~A}} \mathrm{R}$ SPECT radiotracer; D: targeted structures.

\section{Scheme 1. Synthetic route of aryl ketone derivatives $14 a-b^{a}$}

\begin{abstract}
${ }^{a}$ Reagents, conditions and yields: (a) $\mathrm{H}_{2} \mathrm{SO}_{4}$ cc., $\mathrm{MeOH}, 16 \mathrm{~h}$, reflux, $90 \%$; (b) iodoethane, $\mathrm{K}_{2} \mathrm{CO}_{3}, \mathrm{DMF}, 70^{\circ} \mathrm{C}$, overnight, $61 \%$; (c) 2 -fluoroethyl 4-methylbenzenesulfonate, $\mathrm{K}_{2} \mathrm{CO}_{3}$, DMF, $110^{\circ} \mathrm{C}, 2 \mathrm{~h}, 62 \%$; (d) $1 \mathrm{~N} \mathrm{NaOH}$ aq., EtOH, rt, overnight, 94-96\%; (e) CDI, dry THF, rt, $15 \mathrm{~h}$, then potassium 3-ethoxy-3-oxopropanoate, $\mathrm{MgCl}_{2}, 40^{\circ} \mathrm{C}, 24 \mathrm{~h}, 23-36 \%$; (f) tert-butyl 4-(iodomethyl)piperidine-1-carboxylate, $\mathrm{K}_{2} \mathrm{CO}_{3}, \mathrm{DMF}$, rt, $48 \mathrm{~h}$; (g) $\mathrm{KOH}, \mathrm{EtOH} / \mathrm{H}_{2} \mathrm{O}$ (5:1), reflux, 5h, 70-74\% over two steps; (h) TFA, DCM, rt, $1 \mathrm{~h}$; (i) bromomethylcyclohexane, $\mathrm{K}_{2} \mathrm{CO}_{3}, 110^{\circ} \mathrm{C}, 5 \mathrm{~h}, 43-58 \%$ over two steps.
\end{abstract}

\section{Scheme 2. Synthetic route of benzamide derivatives $17 \mathbf{a}-\mathbf{d}^{b}$}

\begin{abstract}
${ }^{b}$ Reagents, conditions and yields: (j) alkyl-halogenated derivatives, $\mathrm{K}_{2} \mathrm{CO}_{3}$, EtOH, reflux, 15-24h, 92-93\%; (k) LiAlH 4 , dry THF, addition $0^{\circ} \mathrm{C}$
\end{abstract} then rt, 1-2h, reflux, 3h, 71-96\%; (l) EDCI, HOBt, Et 3 N, DMF, rt, 18-72h, 17-44\%.

\section{Scheme 3. Synthesis of iodinated compounds $18 \mathrm{a}-\mathrm{f}^{c}$ and ${ }^{125} \mathrm{I}$ radiolabeling of compounds $17 \mathbf{a}-\mathbf{b}^{c}$}

${ }^{c}$ Reagents, conditions and yields: (m) NaI, acetic acid/30\% $\mathrm{H}_{2} \mathrm{O}_{2} 2: 1$, rt, 1-2h, 18-71\%; (n) Na ${ }^{125}$, acetic acid/30\% $\mathrm{H}_{2} \mathrm{O}_{2} 2: 1$, rt, 30 min, $47-61 \%$.

Table 1. 5-HT 4 R affinity for the compounds 14a-b, 17a-d and 18a-f; calculated and measured lipophilicities and permeabilities in the PAMPA-BBB assay with their predictive penetration in the CNS for the compounds 18a-f.

Figure 2. In vivo SPECT imaging showing activity distribution in the brain after injection of $\left[{ }^{125} \mathrm{I}\right] 18 \mathrm{c}$ or $\left[{ }^{125} \mathrm{I}\right] \mathbf{1 8 d}$. Representative MRI images in coronal (A), sagittal (B) and axial (C) planes. Arrows indicate areas of interest: olfactory tubercles (yellow), Caudate-putamen (white) and cerebellum (green). Images of SPECT scan between 10 and 60 minutes after injection of $\left[{ }^{125} \mathrm{I}\right] \mathbf{1 8 c}(\mathrm{D}-\mathrm{F})$ or $\left[{ }^{125} \mathrm{I}\right] \mathbf{1 8 d}(\mathrm{G}-\mathrm{I})$ coregistered with MRI template.

Figure 3. Ex vivo autoradiograms in the brain after injection of $\left[{ }^{125} \mathrm{I}\right] \mathbf{1 8 c}$ or $\left[{ }^{125} \mathrm{I}\right] \mathbf{1 8 d}$. Anatomic atlas templates adapted from the Paxinos and Watson atlas (A), autoradiograms obtained 60 minutes after injection of $\left[{ }^{125} \mathrm{I}\right] \mathbf{1 8 c}(\mathrm{B})$ or $\left[{ }^{125} \mathrm{I}\right] 18 \mathrm{~d}(\mathrm{C}) . \mathrm{Cx}$ : cortex, Ce: cerebellum, Hip: hippocampus, Ip: interpeduncular nucleus, Tu: olfactory tubercles, St: striatum, Thal: thalamus.

Figure 4. In vitro competition between $\left[{ }^{125} \mathrm{I}\right] \mathbf{1}$ and $18 \mathrm{c}, 18 \mathrm{~d}$ or $\mathbf{1}$. Localisation of olfactory tubercles $(\mathrm{Tu})$ is shown in a coronal slice, adapted from the Paxinos and Watson atlas (A). Representative autoradiograms obtained by incubation of $\left[{ }^{125} \mathrm{I}\right] \mathbf{1}$ in the presence of growing concentrations $(0,0.01,0.1,1,10 \mu \mathrm{M}$, from B to F, respectively) of 18c (topline) or 18d (line below) or in the presence of $1 \mu \mathrm{M}$ of $\mathbf{1}(\mathrm{G})$. 
Table 1. 5-HT $\mathrm{H}_{4} \mathrm{R}$ affinity for the compounds 14a-b, 17a-d and 18a-f; calculated and measured lipophilicities and permeabilities in the PAMPA-BBB assay with their predictive penetration in the CNS for the compounds 18a-f.
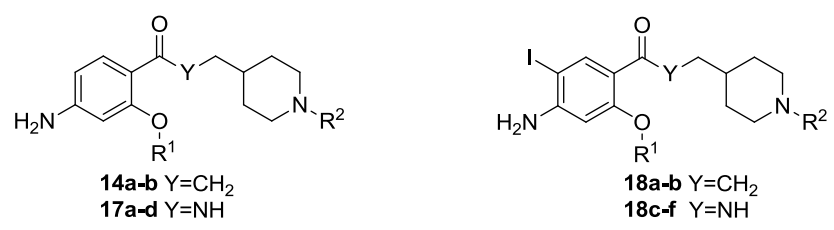

\begin{tabular}{|c|c|c|c|c|c|c|c|c|}
\hline \multirow[b]{2}{*}{ Compound } & \multirow[b]{2}{*}{$\mathbf{Y}$} & \multirow[b]{2}{*}{$\mathbf{R}^{1}$} & \multirow[b]{2}{*}{$\mathbf{R}^{2}$} & \multirow{2}{*}{$\begin{array}{c}K_{\mathrm{i}} 5-\mathrm{HT}_{4} \mathrm{R}(\mathrm{nM}) \\
\text { \% Inhibition } 10^{-6} \mathrm{M} / \mathbf{1 0}^{-8} \mathrm{M}\end{array}$} & \multicolumn{2}{|c|}{ Lipophilicity } & \multicolumn{2}{|c|}{ Permeability } \\
\hline & & & & & $\begin{array}{l}c \log P^{a}- \\
c \log P^{b}\end{array}$ & $\log P$ exp. & $\begin{array}{c}P \mathrm{e} \\
\left(10^{-6} \mathrm{~cm}^{-\mathrm{s}^{-1}}\right)\end{array}$ & Prediction \\
\hline $14 a$ & $\mathrm{CH}_{2}$ & $\mathrm{C}_{2} \mathrm{H}_{5}$ & & $\begin{array}{c}24.7 \pm 5.3(\mathrm{n}=3)^{\mathrm{d}} \\
100 \% / 38 \%\end{array}$ & n.d. & n.d. & n.d. & n.d. \\
\hline $18 \mathbf{a}$ & $\mathrm{CH}_{2}$ & $\mathrm{C}_{2} \mathrm{H}_{5}$ & & $\begin{array}{c}86 \pm 19.4(\mathrm{n}=3)^{\mathrm{d}} \\
100 \% / 65 \%\end{array}$ & $\begin{array}{c}5.06- \\
6.13\end{array}$ & $6.4 \pm 0.5$ & 8.08 & CNS +/- \\
\hline $14 b$ & $\mathrm{CH}_{2}$ & $\mathrm{C}_{2} \mathrm{H}_{4} \mathrm{~F}$ & & $\begin{array}{c}39.9 \pm 5.3(\mathrm{n}=3)^{\mathrm{d}} \\
100 \% / 27 \%\end{array}$ & n.d. & n.d. & n.d. & n.d. \\
\hline $18 b$ & $\mathrm{CH}_{2}$ & $\mathrm{C}_{2} \mathrm{H}_{4} \mathrm{~F}$ & & $\begin{array}{c}521 \pm 261(\mathrm{n}=3)^{\mathrm{d}} \\
100 \% / 22 \%\end{array}$ & $\begin{array}{l}4.91- \\
6.05\end{array}$ & $5.6 \pm 0.4$ & 10.36 & CNS +/- \\
\hline $17 \mathbf{a}$ & $\mathrm{NH}$ & $\mathrm{C}_{2} \mathrm{H}_{5}$ & & $\begin{array}{c}6.9 \pm 0.6(\mathrm{n}=3)^{\mathrm{d}} \\
100 \% / 51 \%\end{array}$ & n.d. & n.d. & n.d. & n.d. \\
\hline $18 c$ & $\mathrm{NH}$ & $\mathrm{C}_{2} \mathrm{H}_{5}$ & & $\begin{array}{c}8.64 \pm 0.37(\mathrm{n}=3)^{\mathrm{d}} \\
100 \% / 20 \%\end{array}$ & $\begin{array}{l}3.95- \\
5.63\end{array}$ & $4.9 \pm 0.5$ & 24.38 & $\mathrm{CNS}+$ \\
\hline $17 b$ & $\mathrm{NH}$ & $\mathrm{C}_{2} \mathrm{H}_{4} \mathrm{~F}$ & & $\begin{array}{c}8.1 \pm 3.4(n=3)^{d} \\
100 \% / 38 \%\end{array}$ & n.d. & n.d. & n.d. & n.d. \\
\hline 18d & $\mathrm{NH}$ & $\mathrm{C}_{2} \mathrm{H}_{4} \mathrm{~F}$ & & $\begin{array}{c}14.7 \pm 2.9(\mathrm{n}=3)^{\mathrm{d}} \\
100 \% / 30 \%\end{array}$ & $\begin{array}{l}3.79- \\
5.55\end{array}$ & $5.2 \pm 0.4$ & 32.29 & $\mathrm{CNS}+$ \\
\hline $17 \mathrm{c}$ & $\mathrm{NH}$ & $\mathrm{CH}_{3}$ & & $\begin{array}{c}\text { n.d. } \\
72 \% / 40 \%^{\mathrm{g}}\end{array}$ & n.d. & n.d. & n.d. & n.d. \\
\hline $18 \mathrm{e}$ & $\mathrm{NH}$ & $\mathrm{CH}_{3}$ & & $\begin{array}{c}13.9 \pm 3.7(\mathrm{n}=3)^{\mathrm{c}} \\
100 \% / 29 \%\end{array}$ & $\begin{array}{c}3.59- \\
5.25\end{array}$ & $5.0 \pm 0.4$ & 31.60 & $\mathrm{CNS}+$ \\
\hline $17 d$ & $\mathrm{NH}$ & $\mathrm{CH}_{3}$ & & $\begin{array}{c}\text { n.d. } \\
79 \% / 5 \%^{\mathrm{g}}\end{array}$ & n.d. & n.d. & n.d. & n.d. \\
\hline
\end{tabular}




\begin{tabular}{|c|c|c|c|c|c|c|c|}
\hline $18 f$ & $\mathrm{NH}$ & $\mathrm{CH}_{3}$ & $\begin{array}{c}68.7 \pm 11.4(\mathrm{n}=3)^{\mathrm{c}} \\
96 \% / 11 \%\end{array}$ & $\begin{array}{c}2.36- \\
3.84\end{array}$ & $3.5 \pm 0.4$ & 22.68 & $\mathrm{CNS}+$ \\
\hline
\end{tabular}

n.d. not determined $/{ }^{\mathrm{a}}$ calculated with MarvinSketch $/{ }^{\mathrm{b}}$ calculated with Molinspiration $/{ }^{\mathrm{c}}$ guinea pig receptors $/{ }^{\mathrm{d}}$ human receptors 
A

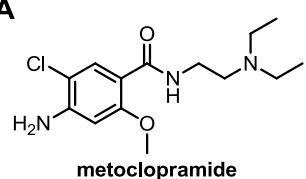

B

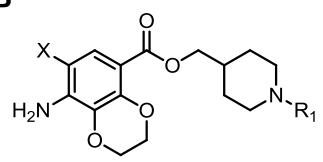

[123] 1 ( $\left.\left.\left({ }^{123}\right]\right]-S B 207710\right), X={ }^{123} \mid, R_{1}=n-B u$ $\left[{ }^{11} \mathrm{C}\right] 2\left(\left[{ }^{11} \mathrm{C}\right]-\mathrm{SB} 207145, \mathrm{X}=\mathrm{Cl}\right), \mathrm{R}_{1}={ }^{11} \mathrm{CH}_{3}$ $\left[{ }^{18} \mathrm{~F}\right] 3$ ( $\left.\left({ }^{18} \mathrm{~F}\right]-\mathrm{MNI}-698, \mathrm{X}=\mathrm{Cl}\right), \mathrm{R}_{1}=\mathrm{C}_{2} \mathrm{H}_{4}{ }^{1{ }^{3} \mathrm{~F}}$

$\left[{ }^{18} \mathrm{~F}\right] 4\left(\left[^{18} \mathrm{~F}\right]-\mathrm{MNI}-699, \mathrm{X}=\mathrm{Cl}\right), \mathrm{R}_{1}=\mathrm{C}_{3} \mathrm{H}_{7}{ }^{18} \mathrm{~F}$
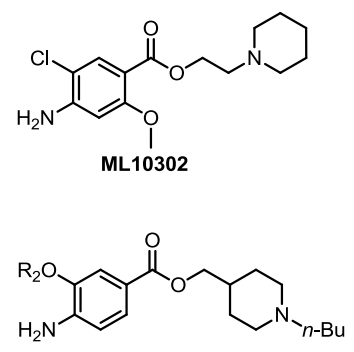

$\left[{ }^{11} \mathrm{C}\right] 5\left(\left[{ }^{11} \mathrm{C}\right]-\mathrm{RX}-1\right), \mathrm{R}_{2}={ }^{11} \mathrm{CH}_{3}$ $\left[{ }^{18} \mathrm{~F}\right] 6\left(\left[{ }^{18} \mathrm{~F}\right]-\mathrm{RX}-2\right), \mathrm{R}_{2}=\mathrm{CD}_{2}{ }^{18} \mathrm{~F}$
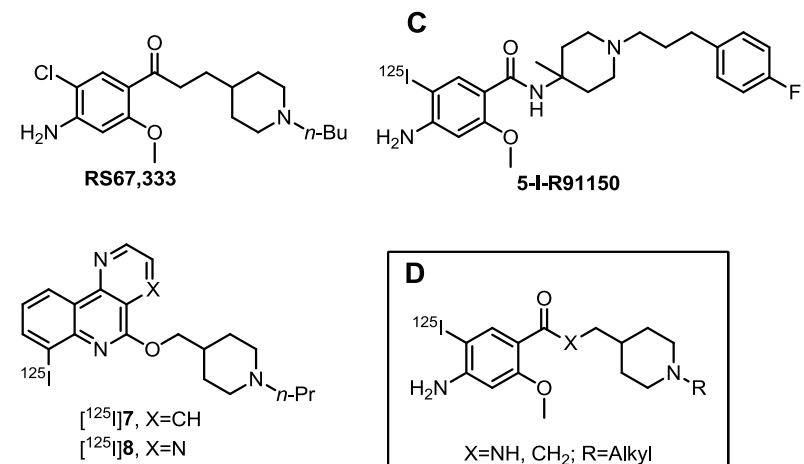


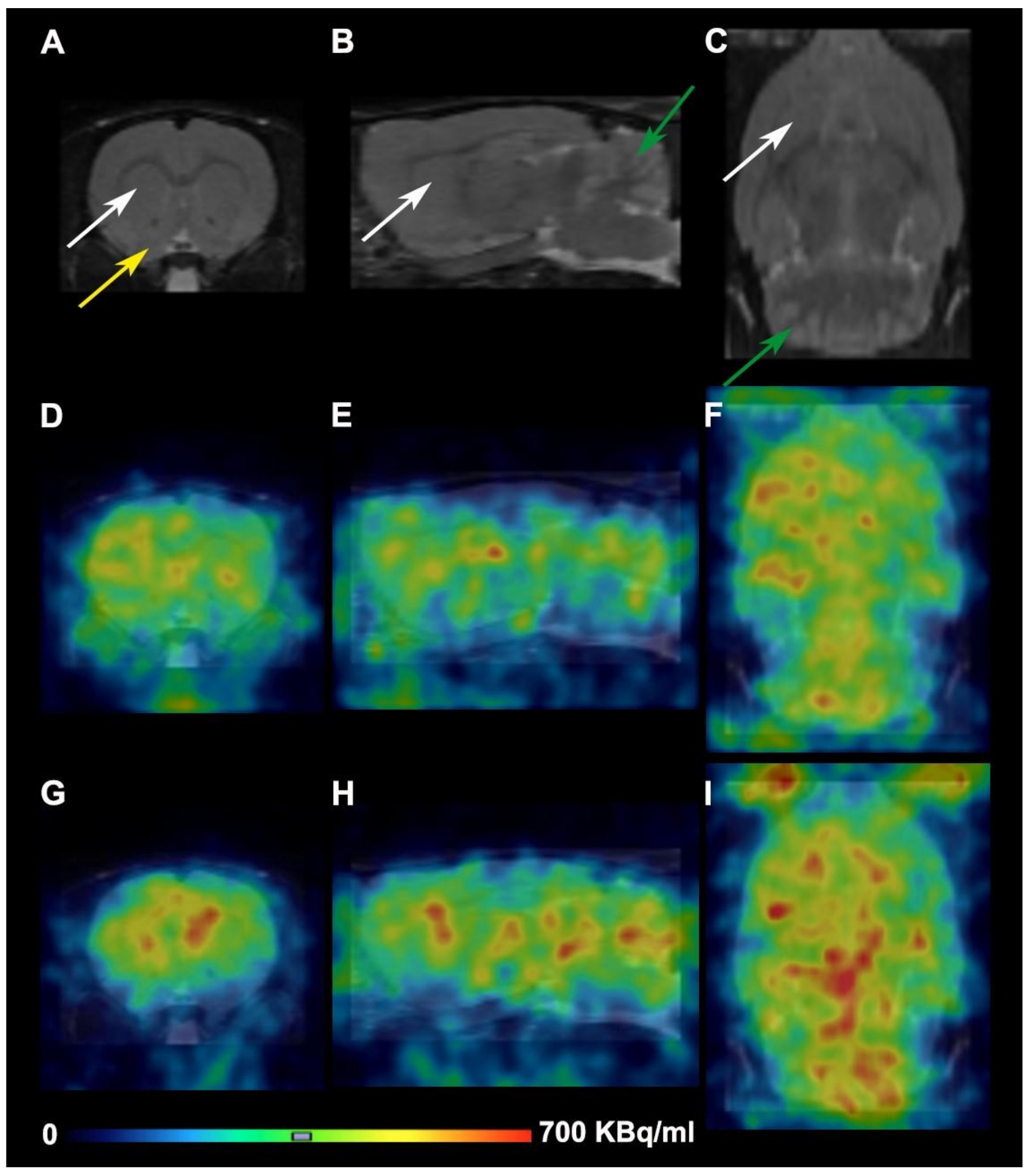



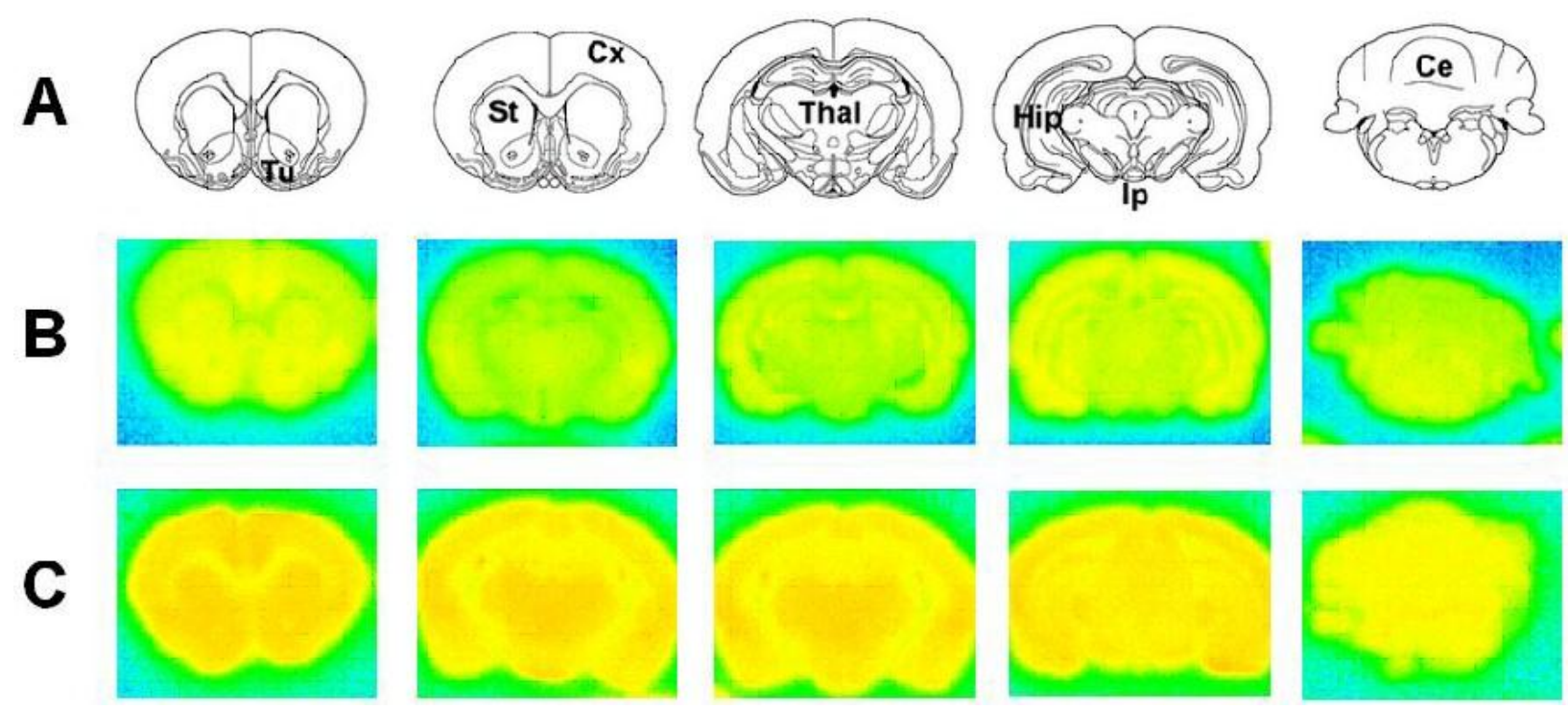


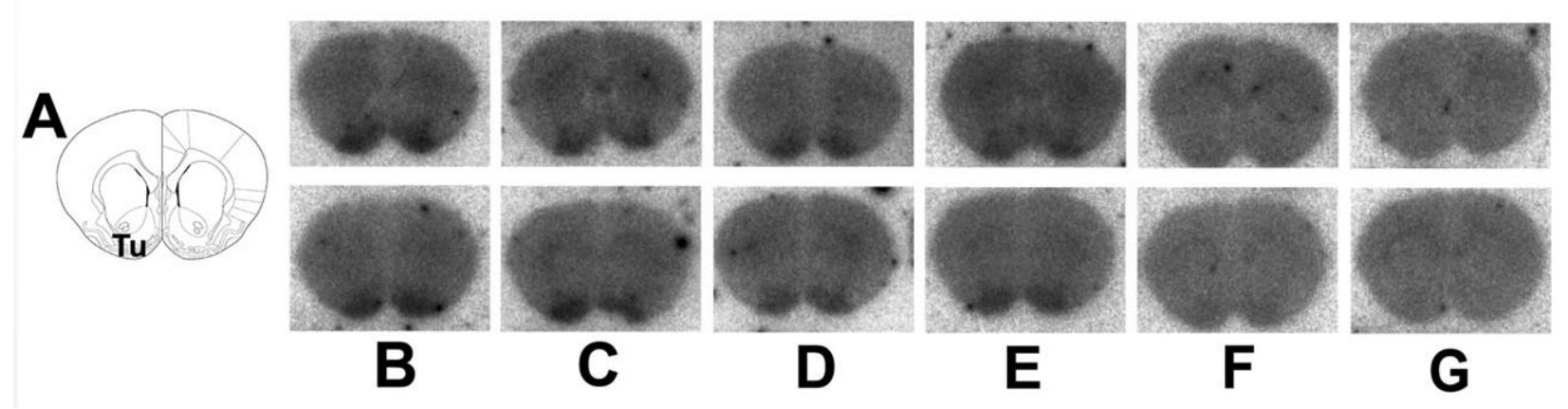



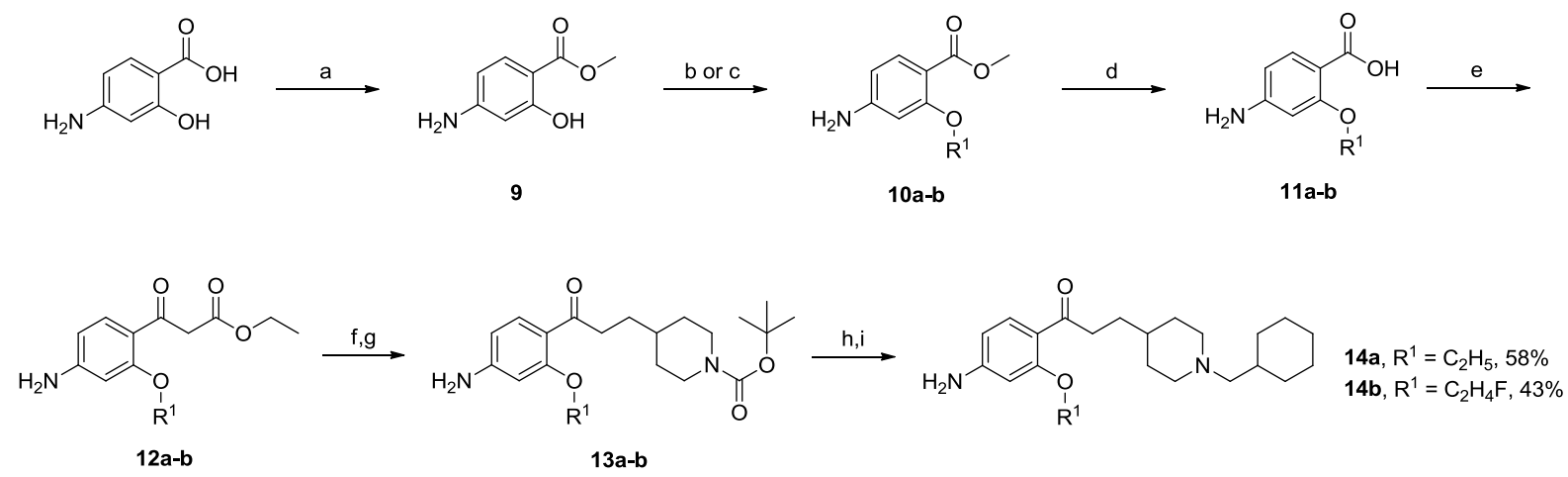


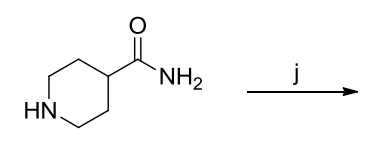<smiles>CCN1CCC(C(N)=O)CC1</smiles>

$15 a-b$

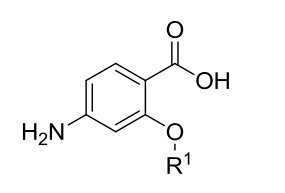

11a-c

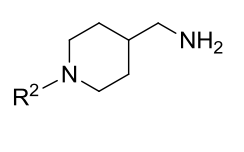

$16 a-b$
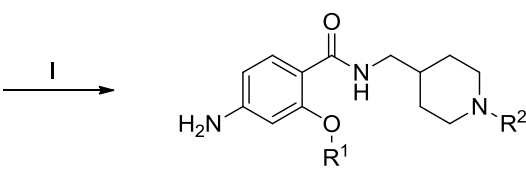

17a, $\mathrm{R}^{1}=\mathrm{C}_{2} \mathrm{H}_{5}, \mathrm{R}^{2}=\mathrm{C}_{7} \mathrm{H}_{13}, 28 \%$ 17b, $\mathrm{R}^{1}=\mathrm{C}_{2} \mathrm{H}_{4} \mathrm{~F}, \mathrm{R}^{2}=\mathrm{C}_{7} \mathrm{H}_{13}, 44 \%$ 17c, $\mathrm{R}^{1}=\mathrm{CH}_{3}, \mathrm{R}^{2}=\mathrm{C}_{7} \mathrm{H}_{13}, 17 \%$ 17d, $\mathrm{R}^{1}=\mathrm{CH}_{3}, \mathrm{R}^{2}=\mathrm{C}_{3} \mathrm{H}_{7}, 25 \%$ 

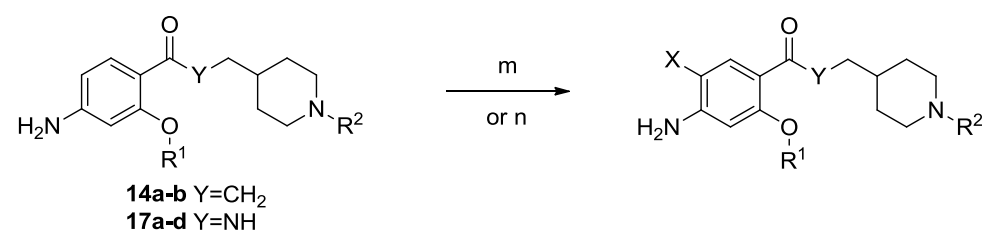

18a, $X=\mathrm{I}, \mathrm{Y}=\mathrm{CH}_{2}, \mathrm{R}^{1}=\mathrm{C}_{2} \mathrm{H}_{5}, \mathrm{R}^{2}=\mathrm{C}_{7} \mathrm{H}_{13}, 18 \%$

18b, $X=I, Y=\mathrm{CH}_{2}, \mathrm{R}^{1}=\mathrm{C}_{2} \mathrm{H}_{4} \mathrm{~F}, \mathrm{R}^{2}=\mathrm{C}_{7} \mathrm{H}_{13}, 41 \%$

18c, $X=I, Y=N H, R^{1}=C_{2} H_{5}, R^{2}=C_{7} H_{13}, 71 \%$

18d, $X=I, Y=N H, R^{1}=\mathrm{C}_{2} \mathrm{H}_{4} \mathrm{~F}, \mathrm{R}^{2}=\mathrm{C}_{7} \mathrm{H}_{13}, 67 \%$

18e, $X=I, Y=N H, R^{1}=\mathrm{CH}_{3}, \mathrm{R}^{2}=\mathrm{C}_{7} \mathrm{H}_{13}, 67 \%$

18f, $X=I, Y=N H, R^{1}=C_{3}, R^{2}=C_{3} H_{7}, 32 \%$

$\left[{ }^{125} \mathrm{I}\right] 18 \mathrm{c}, \mathrm{X}={ }^{125} \mathrm{I}, \mathrm{Y}=\mathrm{NH}, \mathrm{R}^{1}=\mathrm{C}_{2} \mathrm{H}_{5}, \mathrm{R}^{2}=\mathrm{C}_{7} \mathrm{H}_{13}, 47 \%$

$\left[{ }^{125} I\right] 18 d, X={ }^{125} I, Y=N H, R^{1}=C_{2} H_{4} F, R^{2}=C_{7} H_{13}, 61 \%$ 


\section{Synthesis and evaluation of novel serotonin 4 receptor radiotracers for single photon emission computed tomography}

Julien Lalut, ${ }^{a}$ Benjamin B. Tournier, ${ }^{\mathrm{b}}$ Thomas Cailly, ${ }^{\mathrm{a}}$ Cédric Lecoutey, ${ }^{\mathrm{a}}$ Sophie Corvaisier, ${ }^{\mathrm{a}}$ Audrey Davis, ${ }^{a}$ Céline Ballandonne, ${ }^{a}$ Marc Since, ${ }^{a}$ Philippe Millet, ${ }^{b}$ Frédéric Fabis, ${ }^{a}$ Patrick Dallemagne, ${ }^{\mathrm{a}}$ Christophe Rochais ${ }^{\mathrm{a},}$ *

${ }^{a}$ Normandie Univ, UNICAEN, CERMN, F-14032 Caen, France

${ }^{b}$ Hôpitaux Universitaires de Genève, Département de Santé Mentale et de Psychiatrie, Service de Psychiatrie Générale, Unité des Biomarqueurs de Vulnérabilité, Chemin du Petit-Bel-Air, 2, CH-1225 Genève, Switzerland

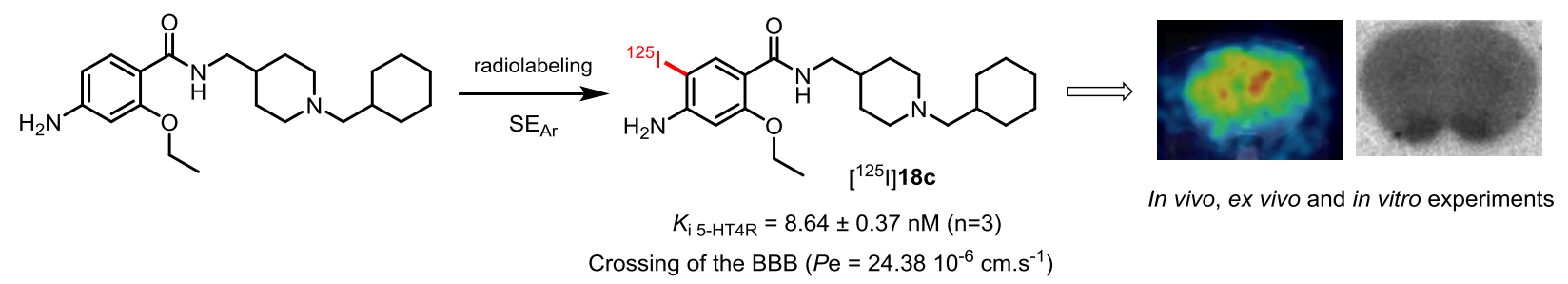

